\title{
Mathematical Modelling and Simulation of the Thermo- Catalytic Decomposition of Methane for Economically Improved Hydrogen Production
}

\author{
Brock Lumbers ${ }^{a}$, David W. Agar ${ }^{b}$, Joachim Gebel ${ }^{\mathrm{a}}$, Frank Platte ${ }^{\mathrm{c}^{*}}$ \\ ${ }^{a}$ Faculty of Technology and Bionics, Rhine-Waal University of Applied Sciences, Kleve, Germany \\ ${ }^{b}$ Faculty of Bio and Chemical Engineering, TU Dortmund University, Dortmund, Germany \\ c Faculty of Life Sciences, Rhine-Waal University of Applied Sciences, Kleve, Germany \\ Email: *Frank.Platte@hsrw.org \\ Address: Marie-Curie Straße 1, 47533 Kleve, Germany \\ DOI: https://doi.org/10.1016/j.ijhydene.2021.11.057
}

\begin{abstract}
The demand for low-emission hydrogen is set to grow as the world transitions to a future hydrogen economy. Unlike current methods of hydrogen production, which largely derive from fossil fuels with unabated emissions, the thermo-catalytic methane decomposition (TCMD) process is a promising intermediate solution that generates no direct carbon dioxide emissions and can bridge the transition to green hydrogen whilst utilising existing gas infrastructure. This process is yet to see widespread adoption, however, due to the high catalyst turnover costs resulting from the inevitable deactivation of the catalyst, which plays a decisive role in the feasibility of the process. In this study, a feasible TCMD process was identified and a simplified mathematical model was developed, which provides a dynamic estimation for the hydrogen production rate and catalyst turnover costs over various process conditions. The work consisted of a parametric study as well as an investigation into the different process modes. Based on the numerous simulation results it was possible to find the optimal process parameters that maximise the hydrogen production rate and minimise the catalyst turnover costs, therefore increasing the economic potential of the process and hence its commercial viability.
\end{abstract}

\section{Keywords}

Turquoise Hydrogen; Thermo-Catalytic Methane Decomposition; Catalyst Deactivation; Catalyst Turnover Costs; Numerical Process Simulation.

\begin{tabular}{ll}
\multicolumn{2}{l}{ Abbreviations } \\
CCS & Carbon Capture and Storage \\
CSTR & Continuous Stirred Tank Reactor \\
FBR & Fluidised Bed Reactor \\
FF & Fluidisation Factor \\
GHG & Greenhouse Gas \\
SV & Space Velocity \\
TCMD & Thermo-Catalytic Methane Decomposition
\end{tabular}




\section{Introduction}

A clean energy future based on hydrogen and renewable electricity, a so-called "hydrogen economy" has been proposed as a feasible alternative to the current combustion of fossil fuels to significantly reduce greenhouse gas (GHG) emissions and the impacts of climate change. However, over $96 \%$ of hydrogen is currently produced from unabated fossil fuels, accounting for $830 \mathrm{Mt}$ of $\mathrm{CO}_{2}$ annually, or roughly $2.5 \%$ of yearly energy-related $\mathrm{CO}_{2}$ emissions [1]. In order for hydrogen to be considered in the future energy mix, it must be produced cleanly without any emissions.

There are various methods to produce hydrogen, each with differing quantities of GHG emissions produced. Colours are often used to classify the level of GHG emissions depending on the hydrogen production method, with the following generally accepted colour scheme given below for the four most common production methods.

- Grey Hydrogen: Produced from fossil fuels with unabated GHG emissions

- Blue Hydrogen: Produced from fossil fuels with abated GHG emissions

- Turquoise Hydrogen: Produced from fossil fuels with no direct GHG emissions

- Green Hydrogen: Produced from renewables with no direct GHG emissions

Transitioning directly to the desired form of green hydrogen through the energy-intensive process of water electrolysis is constrained by the limited capacity of renewable energy systems and challenges in energy storage that are currently not economically scalable to meet the large-scale energy demands of the near future [2], [3]. For high demands, this process cannot be supplied entirely by renewable electricity and as a result, the indirect $\mathrm{CO}_{2}$ emissions by this process can be between two to three times higher than conventional steam-methane reforming methods [4]. Therefore, an intermediate solution is required to reduce emissions in the near future before green hydrogen can be produced at scale.

Blue hydrogen is compatible with existing production methods whilst reducing $\mathrm{CO}_{2}$ emissions through carbon capture and storage (CCS). However, CCS technology requires more studies to ensure that the capture, transportation and storage of $\mathrm{CO}_{2}$ can be done safely with limited consequences of abrupt failures [5]. Many researchers have stated that it would make more sense to avoid the initial production of $\mathrm{CO}_{2}$ emissions rather than spend significant funds to dispose of it at great environmental risk [6]. Additionally, the GHG footprint from blue hydrogen production in recent studies has highlighted the misconception that blue hydrogen enables significant emission reductions with findings from Howarth and Jacobson [7] showing an emissions savings of between $9 \%-12 \%$ compared to grey hydrogen, therefore limiting the widespread use of this pathway as a means of low-emission hydrogen production.

Turquoise hydrogen can be considered an attractive alternative to significantly reduce emissions whilst largely utilising existing gas infrastructure. The most promising method is methane decomposition (methane pyrolysis), which can be modelled by the simplified reaction pathway given in Equation (1). Due to the reaction producing a solid form of carbon, there are no direct GHG emissions ejected into the atmosphere. Furthermore, the carbon generated in solid form is an easier, cheaper and safer by-product to store or dispose of than gaseous carbon [8]. Therefore, many researchers have considered methane pyrolysis to be the most environmentally friendly of all hydrocarbon-based hydrogen production processes and ideal for initiating the transition to a hydrogen economy [9], [10], [11].

$$
\mathrm{CH}_{4}(\mathrm{~g}) \rightarrow \mathrm{C}(\mathrm{s})+2 \mathrm{H}_{2}(\mathrm{~g}) \quad \Delta \mathrm{H}_{r}^{\mathrm{o}}=+74.8 \mathrm{~kJ} / \mathrm{mol}
$$

Through the use of a catalyst, this process is known as thermo-catalytic methane decomposition (TCMD) and is a more favourable method due to the lower energy cost and the creation of high-value carbon by-products when using a metal-based catalyst, which off-set the cost of production [12]. For this reason, other pyrolysis processes such as molten metal, plasma-based pyrolysis and moving-bed systems, which are still largely in development 
were not considered in this study despite showing commercial potential [13]. The problem with the TCMD process, however, is that the catalyst deactivates quickly and therefore must be replaced periodically for sustained hydrogen yields. The route to successful commercialisation of the TCMD process has been hindered by this phenomenon and is further impeded by a limited effort to minimise the catalyst turnover costs or even include these costs in techno-economic models. The majority of research has instead focused on developing complex catalysts to mitigate deactivation and achieve a higher hydrogen yield but the inherent higher turnover costs pose a significant barrier to commercialising this process [6]. The aim of this study was to maximise the economic potential of the process by identifying a potentially viable TCMD system that can be optimised through the development of a simplified mathematical model of the process that estimates the catalyst turnover costs for a given set of process conditions. By simulating the model under different operating conditions and process modes, the process can be optimised to maximise the hydrogen yield whilst minimising the catalyst turnover cost, therefore improving the economics of the process. Additionally, the model better enables the direct analysis of the commercial bottleneck of the TCMD process, which could enhance the early-stage process design and increase the uptake of the TCMD process.

\section{Mathematical Modelling of the TCMD Process}

For the development of the TCMD mathematical model used in this study, a commercially viable system must first be identified. In the research literature, fixed bed reactors and fluidised bed reactors have been suggested as the most promising reactor types for viable turquoise hydrogen production [10], [14], [15]. However, the general consensus among researchers is that fluidised bed reactors are more suitable for large-scale hydrogen production due to the requirement for (semi) continuous operation, which limits the practical use of fixed bed reactors as they face potential reactor clogging issues and periodic replacement of the entire deactivated fixed catalyst bed [16], [17].

Effective catalysts for the TCMD process can be categorised as either (i) carbon materials or (ii) metal-based catalysts. Carbon-based catalysts such as activated carbon and carbon black have several advantages over metalbased catalysts such as availability, durability, stability at higher temperatures, lower cost and tolerance to sulphur poisoning [18], [19], [20]. These benefits are overshadowed by several limitations that inhibit the commercial use of carbon materials compared to metal-based catalysts, such as a lower catalytic activity, rapid deactivation and the generation of low-value carbon by-products [6], [18], [21]. Carbon-based catalysts tend to produce amorphous types of carbon, which are notably less valuable than graphitic carbon such as carbon nanotubes (CNT) produced by certain metal-based catalysts [6]. Overall, carbon-based catalysts have a low catalytic activity toward the TCMD reaction and although do not have high catalyst turnover costs, the revenue generated by the carbon by-product, which has been stated as a critical factor for the feasibility of the TCMD process, is vastly lower than that of metal-based catalysts, limiting their commercial use [22].

According to Muradov [23], almost all transition metals display catalytic activity towards the TCMD reaction. From a commercial perspective, cheap and abundant catalysts are more suitable compared to expensive precious metals such as $\mathrm{Rh}, \mathrm{Ru}, \mathrm{Pd}$ and $\mathrm{Pt}$, despite their reported high catalytic activity [24]. Of the transition metals, $\mathrm{Ni}, \mathrm{Co}$ and $\mathrm{Fe}$ are the most studied catalysts in the research literature, although cobalt is less often considered as a viable catalyst due to toxicity issues and high costs, which limit its commercial use [21]. A comparison of the catalytic activity of the three metals for the TCMD reaction reveals $\mathrm{Ni}>\mathrm{Co}>\mathrm{Fe}$ [21], [25]. The main advantage of nickel catalysts is that they exhibit the highest catalytic activity in temperatures between $600-700 \circ \mathrm{C}$ despite being limited to this narrow operating window and the $60 \%$ maximum equilibrium conversion limit at this temperature [26]. Fe-based catalysts, however, have been shown to be more stable at higher temperatures and have a significantly higher catalytic activity than nickel above 700ㄷ [21], [27]. Catalyst stability at high temperatures is important for the TCMD process as increased temperatures are known to favour the conversion of methane and therefore increase hydrogen yields. Other advantages of Fe catalysts are that 
they are cheaper, more abundant and found to produce more ordered forms of graphitic carbon and carbon nanotubes than other metal-based catalysts, which have a higher value and can be used to reduce the hydrogen production cost [6], [25], [27]. A market assessment suggests that graphitic carbon and carbon fibers have a price range of approximately $\$ 10 / \mathrm{kg}$ and $\$ 25-113 / \mathrm{kg}$, respectively [22]. Works by Cornejo [6] found that forms of iron ore, such as hematite, despite lower carbon yields was the most cost-effective catalyst with reported turnover costs of less than half that of any other catalyst in the research literature. These findings have been verified in recent studies, which claim iron-based catalysts are the most cost-effective, which is the most important parameter given the catalyst turnover costs have been identified as the commercial bottleneck to the TCMD process [28], [29], [30]. Therefore, an iron ore catalyst was selected for this study.

Deactivation of Fe-based catalysts occurs due to fouling of various forms of solid encapsulating carbon blocking the active sites of the catalyst [6]. The use of catalyst regeneration was found to be unsuitable for this study due to the production of emissions, reduced catalytic activity after repeated catalyst cycles and high cost compared to the cheap catalysts utilised [31]. The most cost-effective method of mitigating catalyst deactivation was therefore given by parametric optimisation.

In summary, the most promising commercially viable solution featured the use of a fluidised bed reactor (FBR) for semi-continuous operation with an iron-ore catalyst due to their low cost, stability at higher temperatures and high-value carbon by-products [32]. The following model is a simplified approach to modelling the TCMD process and providing a dynamic estimate for the catalyst turnover costs and hydrogen production rate. The model was based on the simplified schematic of the TCMD process for a single reactor configuration given in Figure 1 and the model assumptions given in Appendix A.

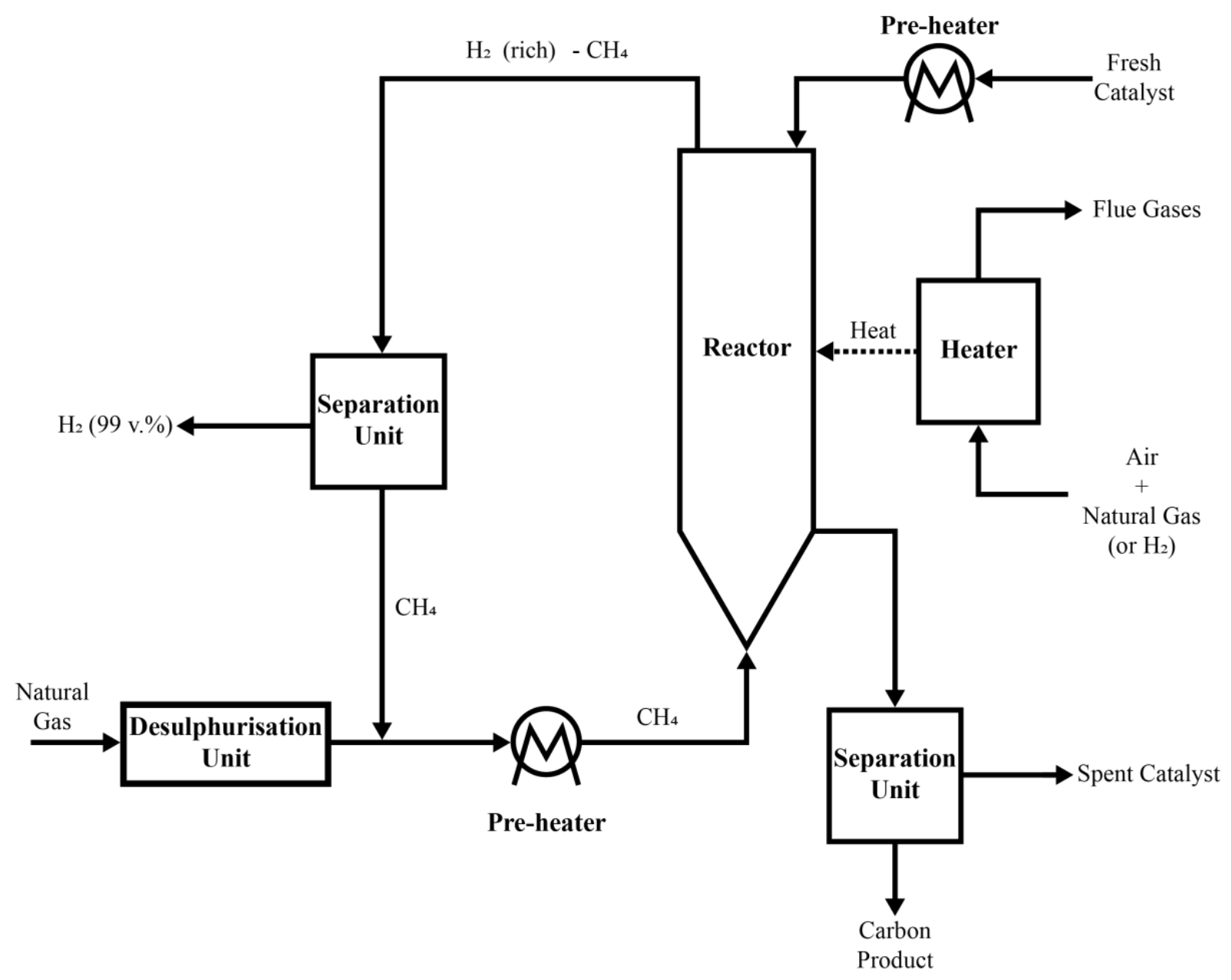

Figure 1. Simplified TCMD process flow diagram for a single reactor configuration. 


\subsection{Mass and Energy Balances}

In an FBR, the interactions between the catalyst and gas particles are complex to model, however, the system can be simplified and effectively modelled as a continually stirred tank reactor (CSTR) since the catalyst bed is well-mixed with high rates of heat and mass transfer due to fluidisation [21], [33], [34]. The species balance equations for the reaction are given by:

$$
\begin{gathered}
\frac{d C_{C H_{4}}}{d t}=\left(F_{C H_{4}, i}-F_{C H_{4}, i}(1-X)-r_{C H_{4}} W\right) / V \\
\frac{d C_{H_{2}}}{d t}=\left(F_{H_{2}, i}-2 F_{C H_{4}, i} X+2 r_{C H_{4}} W\right) / V \\
\frac{d C_{C}}{d t}=\left(F_{C, i}-F_{C H_{4}, i} X+r_{C_{4}} W\right) / V
\end{gathered}
$$

Where at steady state, the balances represent the ideal fluidised CSTR design equation:

$$
W=\frac{F_{C_{4}, i} X}{r_{C_{4}}}
$$

Due to intensive mixing, the energy balance of the TCMD process can be formulated using a pseudohomogeneous approach as given in Equation (6) and accounts for the four major fluxes based on convection, heat loss through jacket (neglected), heat of reaction and external heating. This approach assumes that the volumetric heat capacity of the gas phase is considered negligible compared to the solid phase and the temperatures of each phase are approximately equal.

$$
\frac{d T}{d t}=\frac{1}{\overline{\rho_{s}} \overline{\mathrm{V}} \overline{c_{p}}}\left(Q_{i} \rho_{g} c_{p}\left(T_{i}-T\right)+U \mathrm{~A}_{r}\left(T-T_{a}\right)+r_{C H_{4}} \mathrm{~W}\left(-\Delta \mathrm{H}_{r}\right)+\dot{\mathrm{Q}}\right)
$$

\subsubsection{Thermodynamics}

The maximum methane conversion can be calculated by taking the equilibrium composition of methane and hydrogen in the gas phase only, although the solid carbon is known to have a small influence on the equilibrium [35], [36].

$$
\mathrm{K}_{\mathrm{p}}=\frac{\left(p_{\mathrm{H}_{2}}\right)^{2}}{p_{\mathrm{CH}_{4}}}
$$

The equilibrium constant is also given by the change in Gibbs free energy and reaction temperature as shown by Equation (8) for low-pressure gases.

$$
\mathrm{K}_{\mathrm{eq}}=\mathrm{K}_{\mathrm{f}} \mathrm{K}_{\mathrm{p}}\left(p^{o}=1 \text { bar }\right)^{-\Delta v}=\exp \left(\frac{-\Delta G^{o}}{R T}\right)
$$

Where many publications reference the correlation given by Equation (9) [31].

$$
\Delta G^{o}=89,658.88-102.27 \mathrm{~T}-0.00428 \mathrm{~T}^{2}-2,499,358.99 / \mathrm{T}
$$

The equilibrium conversion can then be found by solving Equation (10).

$$
\mathrm{K}_{\mathrm{eq}}=\mathrm{K}_{\mathrm{x}} \mathrm{p}^{\Delta \mathrm{v}}=\frac{\left(y_{\mathrm{H}_{2}}\right)^{2} \mathrm{p}^{2}}{y_{\mathrm{CH}_{4}} \mathrm{p}}=\frac{\left(\frac{2 X_{e q}}{1+2 X_{e q}}\right)^{2} \mathrm{p}}{\left(\frac{1-X_{e q}}{1+2 X_{e q}}\right)}
$$

The maximum conversion can then be plotted over the entire temperature range. 


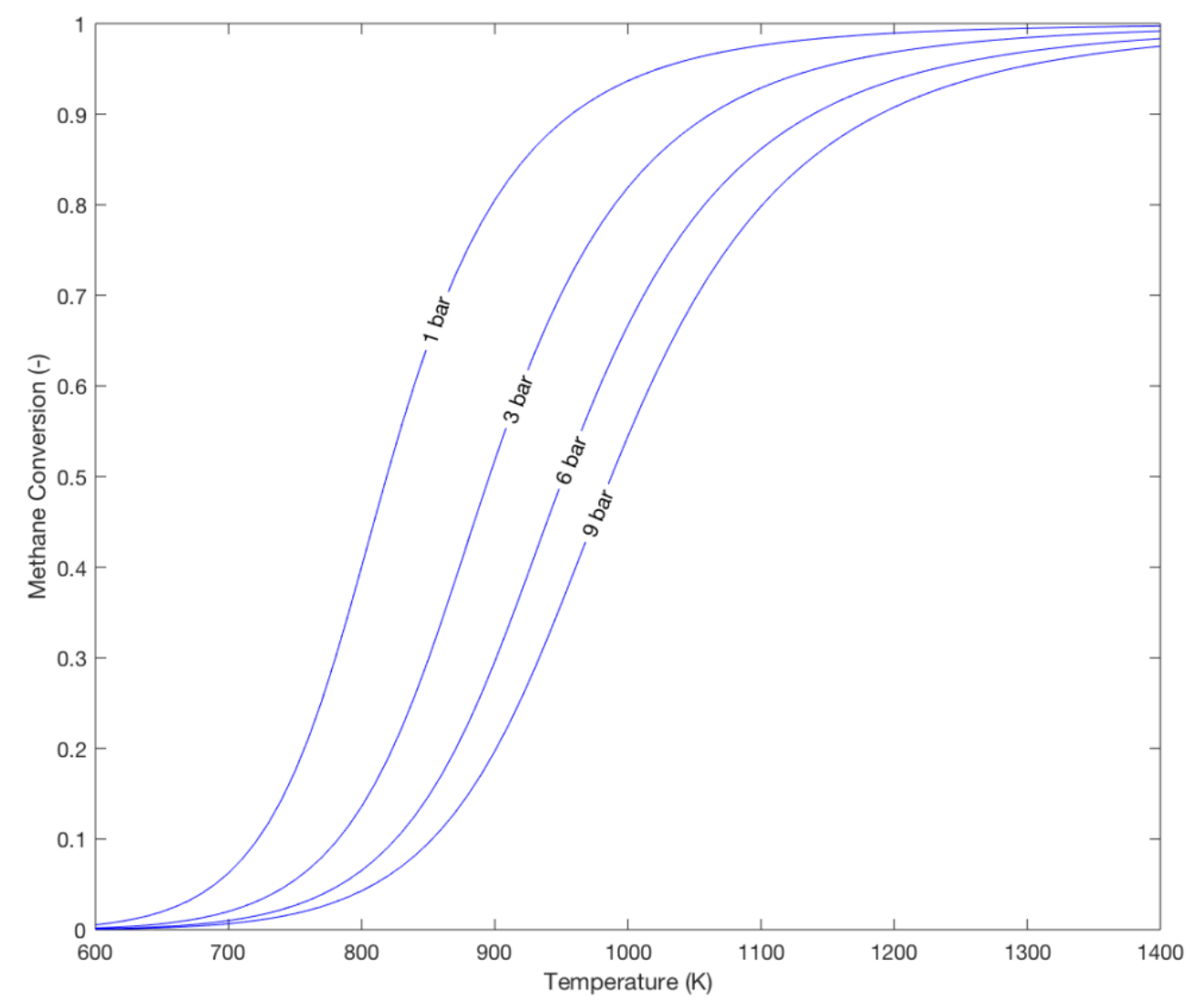

Figure 2. Equilibrium conversion of methane for various reactor pressures.

\subsubsection{Kinetics}

The TCMD reaction mechanism utilising a metal-based catalyst was initially proposed by Grabke [37] and has since been widely accepted by various researchers [21], [23], [38]. For the use of an iron ore catalyst $\left(\mathrm{Fe}_{2} \mathrm{O}_{3} / \mathrm{Fe}_{3} \mathrm{O}_{4}\right)$, very few publications have modelled the kinetics of the TCMD reaction. However, for the thermal decomposition of methane and for some metal-based catalysts, researchers generally agree that the overall reaction follows first-order kinetics (although other orders reported) and therefore, a simplified first-order rate law for the TCMD reaction was found to be suitable [18], [39], [40], [41]. Zhou et al. [42] experimentally carried out the TCMD reaction in a fluidised bed reactor using an iron ore catalyst and the results were then used to calculate the frequency factor and activation energy for the Arrhenius equation. The rate law and rate constant equation are given below, where $a$ is the catalyst activity [18].

$$
\begin{gathered}
-r_{C_{4}}=k(T)\left(C_{C_{4}}-\frac{1}{\mathrm{~K}_{\mathrm{eq}}} C_{H_{2}}\right) a \\
k(\mathrm{~T})=A \mathrm{e}^{-\mathrm{E}_{a} / \mathrm{RT}}
\end{gathered}
$$

The isokinetic reaction rates can then be plotted on the X-T diagram. 


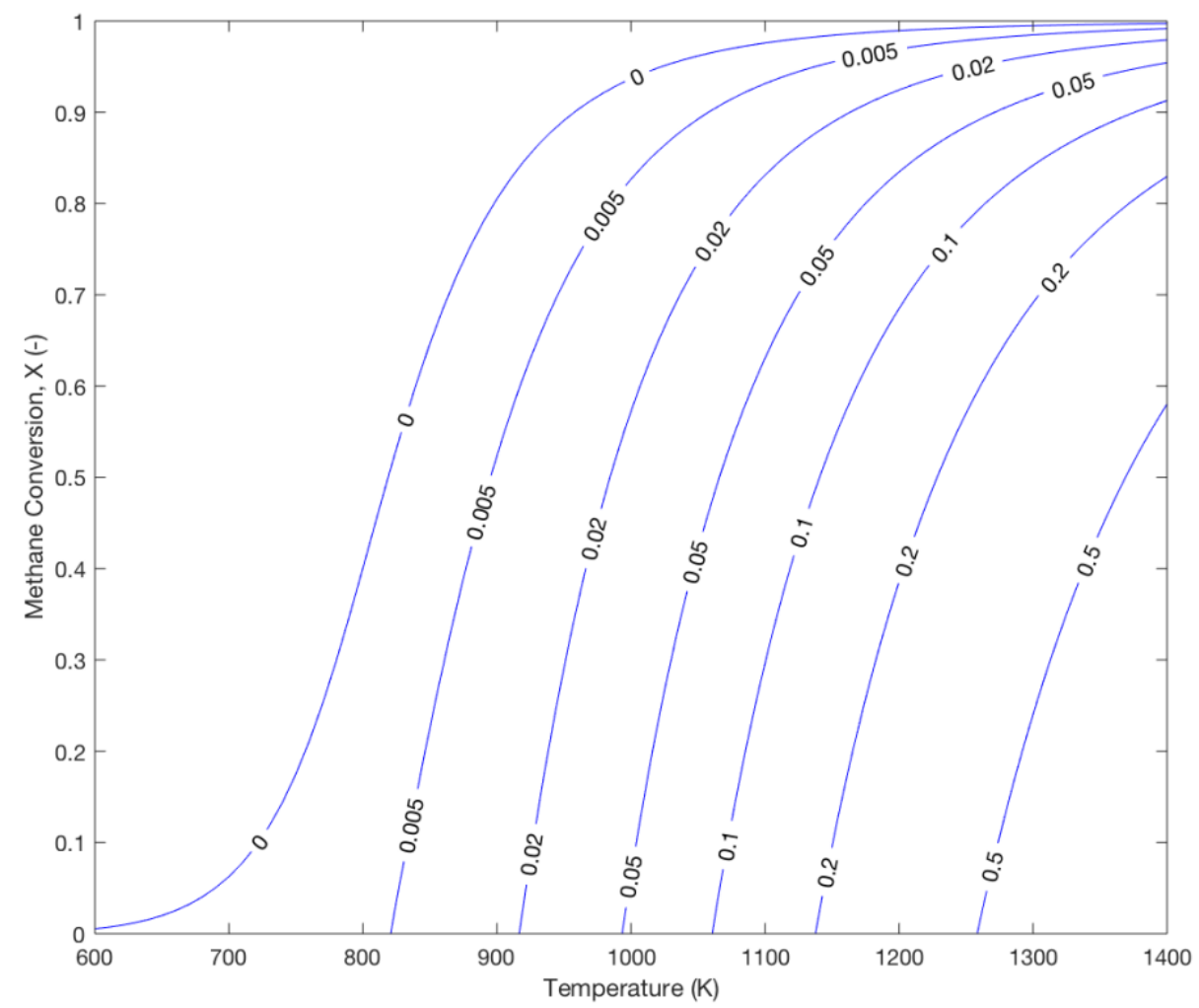

Figure 3. Isokinetic lines for the TCMD process (mol/kg cat s) (conditions: $p=1$ bar, $C_{C H 4, i}=1 \mathrm{~mol} / \mathrm{m}^{3}$ ).

\subsection{Catalyst Deactivation}

A major drawback associated with the use of catalysts for the TCMD process is their rapid deactivation. It is inevitable that all catalysts will deactivate, although with varying time frames and deactivation mechanisms depending on the process and catalysts involved [43].

\subsubsection{Mechanisms of Catalyst Deactivation}

Catalyst deactivation can be classified into six distinct mechanisms. Table 1 provides an overview of the six catalyst deactivation mechanisms and categorises them depending on their type.

Table 1. Overview of catalyst deactivation mechanisms [44].

\begin{tabular}{|c|c|c|}
\hline Mechanism & Type & Description \\
\hline Poisoning & Chemical & $\begin{array}{l}\text { Strong chemisorption of species on catalytic sites } \\
\text { which block the active sites for catalytic reactions }\end{array}$ \\
\hline Fouling & Mechanical & $\begin{array}{l}\text { Physical deposition of species from fluid phase onto } \\
\text { the catalytic surface and in the catalyst pores }\end{array}$ \\
\hline Sintering & Thermal/Chemical & $\begin{array}{l}\text { Thermally induced loss of catalytic surface area, } \\
\text { support area and active phase-support reactions }\end{array}$ \\
\hline Vapour Formation & Chemical & $\begin{array}{l}\text { Reaction of gas with the catalyst phase to produce } \\
\text { a volatile compound }\end{array}$ \\
\hline $\begin{array}{l}\text { Vapour-Solid and Solid-Solid } \\
\text { Reactions }\end{array}$ & Chemical & $\begin{array}{l}\text { Reaction of vapour, support, or promoter with } \\
\text { catalytic phase to produce an inactive phase }\end{array}$ \\
\hline Attrition/Crushing & Mechanical & $\begin{array}{l}\text { Loss of catalytic material due to abrasion or } \\
\text { mechanical-induced crushing of the catalyst particle }\end{array}$ \\
\hline
\end{tabular}


In the TCMD process, the dominant deactivation mechanism is fouling, which occurs due to the deposition of solid carbon in the form of carbon filaments and encapsulating carbon, which blocks the active sites on the surface of the catalyst [27], [35], [45].

\subsubsection{Catalyst Deactivation Model}

The deactivation model for this study assumes separable kinetics, with the relative catalyst activity given by:

$$
a=\frac{-r_{\mathrm{CH}_{4}}}{-r_{C \mathrm{CH}_{4} i}}
$$

Where,

$$
\frac{d a}{d t}=r_{d}
$$

The catalyst deactivation rate, $r_{d}$, was also modelled through a simplified power law, with the values 0.8 and -0.4 empirically found to correlate well with experimental data in the research literature and the overall deactivation order was comparable to previously used metal-based kinetic models [46]. It should be noted that the catalyst activity ' $a$ ', could be replaced by the end term since the catalyst activity has been reported to remain at a steady state activity value ' $a_{s s}$ ', instead of complete deactivation [47].

$$
-r_{d}=-\frac{d a}{d t}=k_{d}\left(C_{C H_{4}}\right)^{0.8}\left(C_{H_{2}}\right)^{-0.4}\left(\frac{a-a_{S S}}{1-a_{S s}}\right)
$$

Where,

$$
k_{d}(\mathrm{~T})=\mathrm{A}_{d} e^{-E_{d} / \mathrm{RT}}
$$

A study conducted by Amin [35] was used to extract data for the above equations, although this study makes use of a different catalyst, the deactivation mechanism was thought to still be applicable. According to Al-Fatesh et al. [48] when the temperature exceeds $950^{\circ} \mathrm{C}$, the dominating deactivation mechanism becomes catalyst sintering, which indirectly causes an acceleration in the rate of deactivation [6], [15]. To reflect this behaviour in the model, the deactivation rate constant can be simply adjusted when exceeding $950{ }^{\circ} \mathrm{C}$ to increase the deactivation rate.

\subsection{Fluidised Bed Reactor}

Although the model is simplified as a CSTR, there are a number of unique features of an FBR that must be considered. The model must ensure the fluidisation of the catalyst particles, which allows for the initial assumption of well-mixed behaviour. To determine the minimum fluidisation velocity $\left(U_{m f}\right)$ in an FBR, the Wen and $\mathrm{Yu}$ [49] empirical correlation for small particles is used, which results in the following approximate equation [27].

$$
U_{m f}=\frac{d_{p}^{2}\left(\rho_{c a t}-\rho_{g}\right) g}{1650 \mu_{g}}
$$

The terminal (maximum) velocity can be calculated via Stokes law, assuming spherically shaped catalyst particles.

$$
U_{t}=\frac{d_{p}^{2}\left(\rho_{c a t}-\rho_{g}\right) g}{18 \mu_{g}}
$$

When $U_{f}$ is greater than $U_{m f}$, the excess gas is assumed to pass through the reactor as bubbles, with their size increasing as the fluidisation velocity increases [50]. 


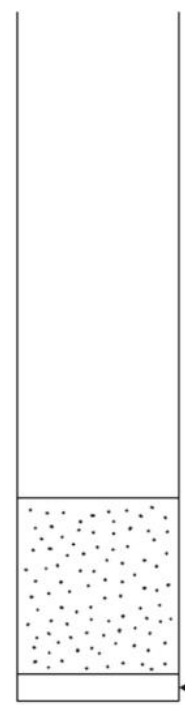

Fixed Bed
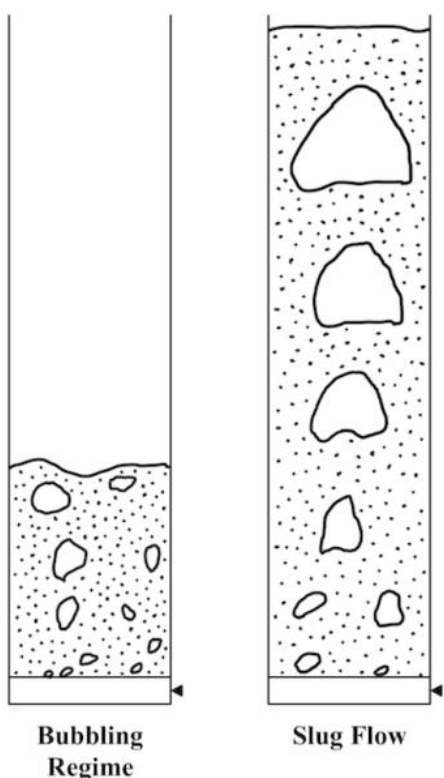

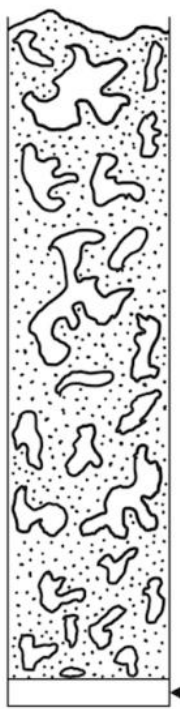

Turbulent

Regime

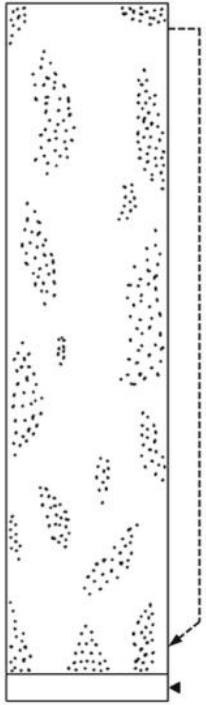

Fast

Fluidization

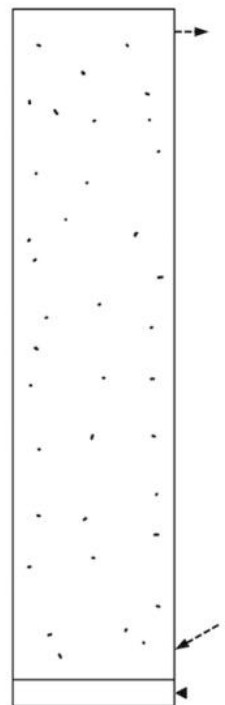

Pneumatic

Conveying

Increasing $\mathbf{U}_{\mathrm{f}}$

Figure 4. Different flow patterns in a fluidised bed reactor.

Due to this, less methane gas comes into contact with the catalyst, which decreases the methane conversion. Without modelling the fluidisation process in great detail, this effect can only be approximated. A simplified modelling approach was to develop a parameter called the "fluidisation factor" (FF), which represents the relationship between fluidisation velocity and the conversion as a result of the unreacted methane contained in the bubbles. It is assumed that at $U_{m f}$, where no bubbles are present, $\mathrm{FF}=1$, whilst at $U_{t}$ the $\mathrm{FF}$ can be approximated to equal 0.7 after analysing results by Amin [35]. The following correlation was then developed based on these findings and under the assumption of Geldart Type-A catalyst particles.

$$
F F=\left(1+0.139 U_{m f}\right) e^{\frac{-0.358 U_{f}}{U_{t}}}
$$

Including the effect of the fluidisation factor, the equation for the conversion of methane is then given by:

$$
X_{C_{4}}=F F \frac{F_{C H_{4}, i}-F_{C H_{4}, o}}{F_{C_{4}, i}}
$$

\subsection{Catalyst Turnover Costs}

The catalyst turnover costs are defined as the total cost of spent catalyst per tonne of hydrogen produced. To calculate the real-time and average catalyst turnover costs, the time estimate for one catalyst cycle and the time estimate for producing one tonne of hydrogen must be defined:

$$
\begin{gathered}
t_{\text {cycle }}=\frac{\left(1-a_{\text {limit }}\right)}{r_{d}} \\
t_{\text {tonne } \mathrm{H}_{2}}=\frac{1000 \mathrm{~kg}}{2.016 \times 10^{-3} \frac{\mathrm{kg}}{\mathrm{mol}}\left(F_{\mathrm{H}_{2}}-Q_{i} C_{\mathrm{H}_{2}, i}\right)}
\end{gathered}
$$

The number of catalyst cycles per tonne of hydrogen produced can then be calculated.

$$
N_{\text {cycles }}=\frac{t_{\text {tonne } \mathrm{H}_{2}}}{t_{\text {cycle }}}
$$


Finally, the catalyst turnover costs can be calculated through Equation (24). It was found that the iron ore catalyst costs approximately $€ 0.06$ per $\mathrm{kg}$ (Apr, 2020) [51]. Since the two time estimates are dynamic, the average costs are calculated by finding the average turnover cost value over the duration of the catalyst cycle.

$$
\text { CT Costs }\left(€ / \text { tonne } H_{2}\right)=W \times N_{\text {cycles }} \times € 0.06
$$

The following optimisation ratio then quantified the simulation results.

$$
\text { Minimise }\left\{\frac{\text { Avg. Catalyst Turnover Costs }}{\text { Hydrogen Production Rate }}\right\}
$$

\subsection{Heating Strategy}

The heating strategy and type of process mode that results, has a large influence on the TCMD process. This can be observed on an X-T diagram, where, several reaction pathways exist depending on the chosen heating strategy. The four process modes studied in this work were; (1) isothermal, (2) isokinetic, (3) adiabatic and (4) constant heating, which was subdivided into (4a) low, (4b) medium and (4c) high. A qualitative reaction pathway for each process mode is given in Figure 5 and labelled with the respective enumerated value.

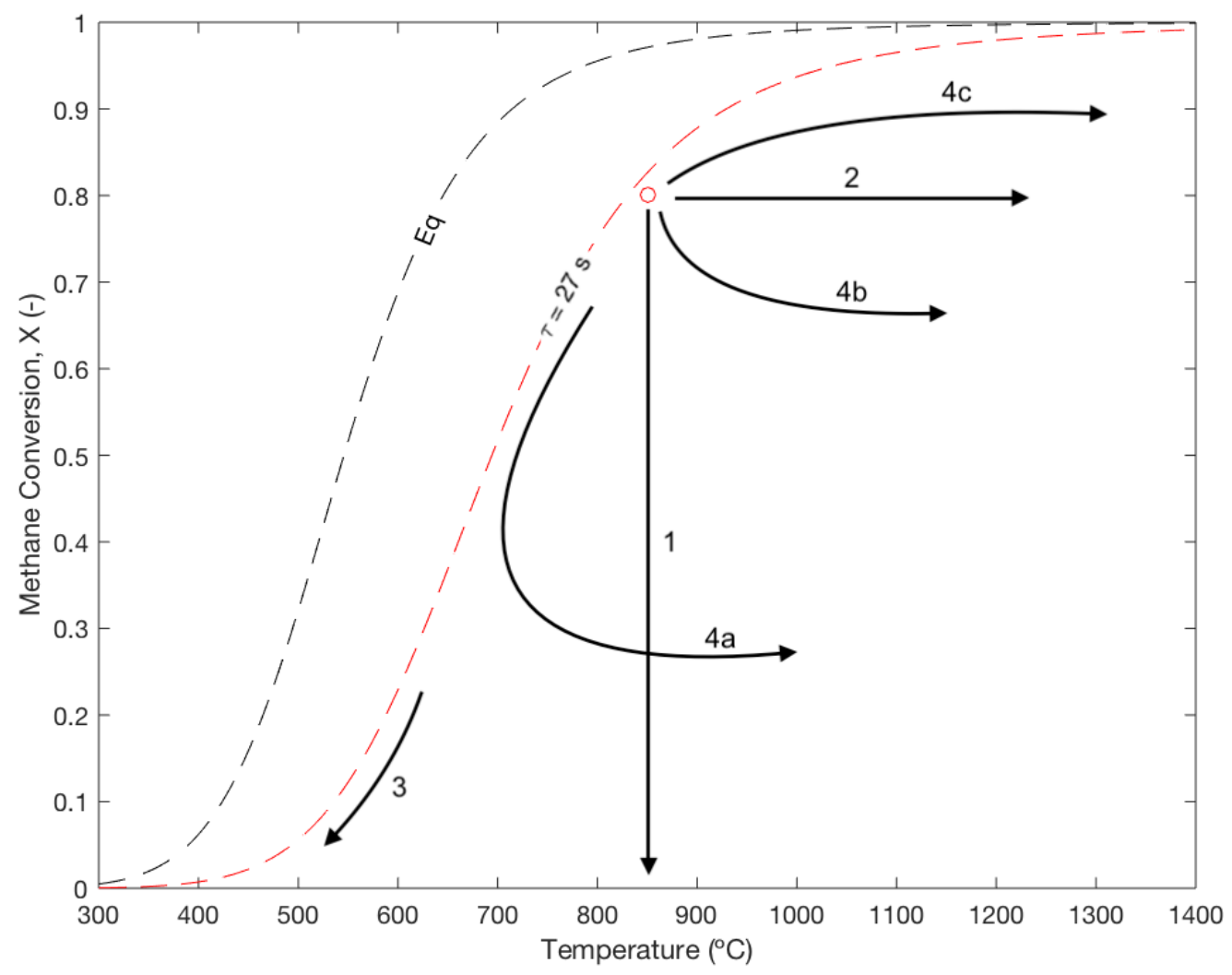

Figure 5. Qualitative reaction pathways for different process modes (initial conditions $T=850 \circ \mathrm{C}, \mathrm{p}=1 \mathrm{bar}, \mathrm{SV}=$ 3.5 L/g cat h).

The isothermal process mode is the most common in experimental studies due to the thermal stability. The isokinetic and constant heating process modes typically obtain higher conversion rates but with elevated temperatures, depending on the desired level of hydrogen production and external heat applied. The adiabatic process mode is not a viable method for continual hydrogen production since the reaction is endothermic and requires constant heating. The influence of the heating strategy is discussed in section 3.2.7. 


\subsection{Model Solution}

The model was first discretised and then solved using the Euler method for numerical integration since it is simple and robust. The following set of differential equations, which take into account the model assumptions, were used to solve the model in addition to the defined initial conditions given in Appendix B. The remaining equations given in this paper were arranged in an appropriate order and solved algebraically.

$$
\begin{aligned}
& C_{C H_{4}, k+1}=C_{C H_{4}, k}+\Delta t\left[\frac{1}{\mathrm{v}}\left(Q_{i} C_{C_{4} i}-Q_{o} C_{C_{4}, k}-r_{C_{4}} W\right)\right] \\
& C_{H_{2}, k+1}=C_{H_{2}, k}+\Delta t\left[\frac{1}{\mathrm{v}}\left(Q_{i} C_{H_{2} i}-Q_{o} C_{H_{2}, k}+2 r_{C_{H_{4}}} W\right)\right] \\
& T_{k+1}=T_{k}+\Delta t\left[\frac{1}{\bar{\rho} \overline{c_{p}} \overline{\mathrm{V}}}\left(Q_{i} \rho_{g} c_{p}\left(T_{i}-T_{k}\right)+r_{C H_{4}} W\left(-\Delta \mathrm{H}_{r}\right)+\dot{\mathrm{Q}}\right)\right]
\end{aligned}
$$

To validate the model, the dynamic deactivating behaviour was first compared with experimental results from Basset et al. [52] and Basset et al. [53] for similar operating conditions as shown in

Figure 6. The model displayed similar behaviour over time and fit between the two conversion curves for the two different iron-based catalysts. Validating the model in relation to the catalyst turnover costs, found that the model was accurate to within $6 \%$ and $10 \%$ to results obtained by Cornejo [6] for a single reactor configuration at isothermal conditions and pressures of 1 bar and 9 bar respectively. The model was concluded to be suitable for the purpose of the study.

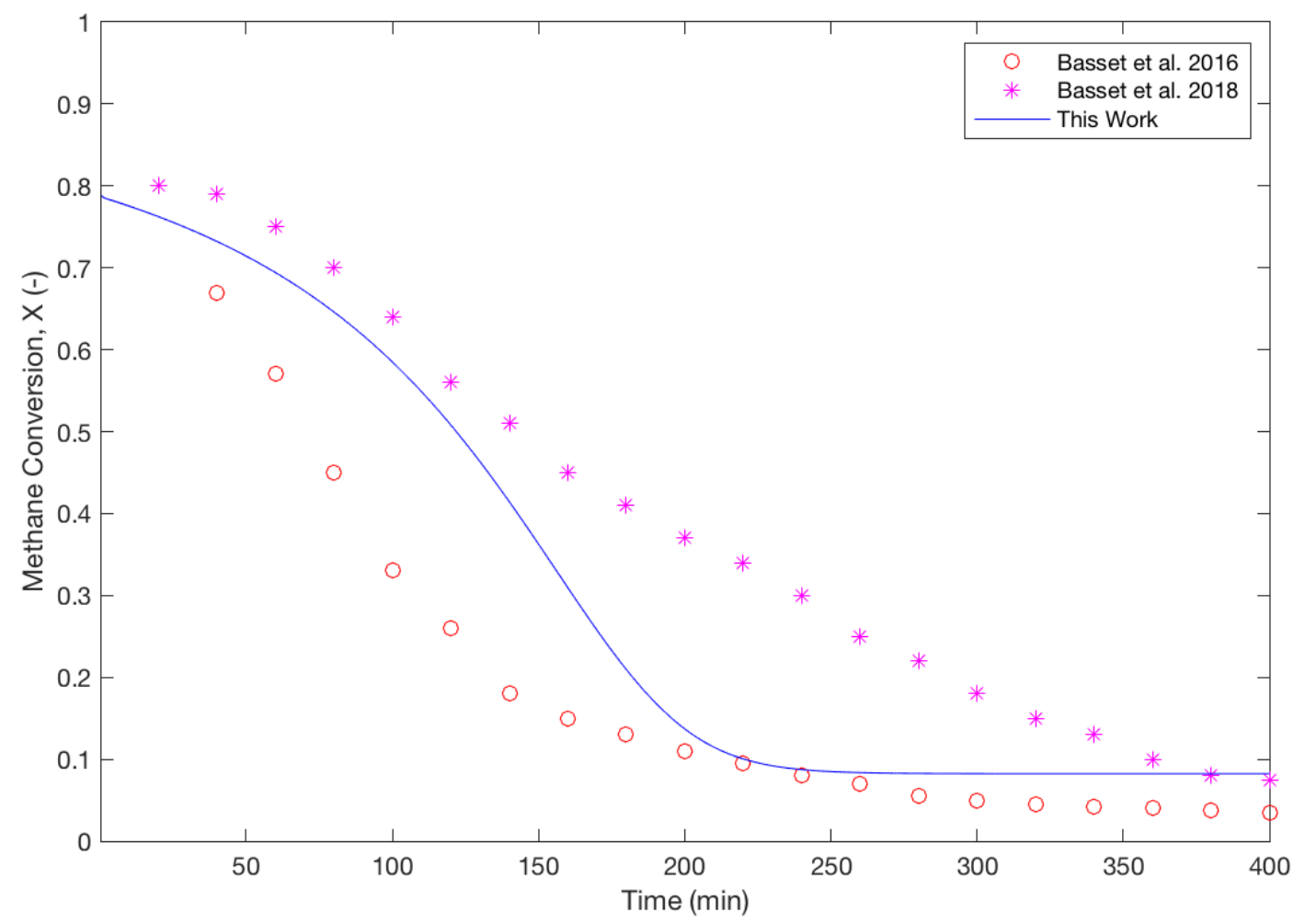

Figure 6. Model validation through dynamic conversion comparison (This work: $\mathrm{T}=850^{\circ} \mathrm{C}, \mathrm{p}=1$ bar, $\mathrm{SV}=3.5$ L/g cat h). 


\section{Results and Discussion}

The TCMD Model developed in this study allowed for the dynamic estimation of the catalyst turnover costs and the hydrogen production rate. Numerous simulation studies were carried out to determine the optimal operating conditions of the process as well as a parametric study that assessed the influence of each process parameter on the catalyst turnover costs and hydrogen production rate.

\subsection{Optimal Operating Conditions}

The optimal operating conditions were defined as those that maximise the economic potential of the process.

Table 2 presents a summary of the optimised process conditions for the TCMD process, whilst Figure 7 displays the deactivation behaviour of the optimised TCMD process over two catalyst cycles. Detailed information related to the effect of each parameter is discussed in the following section. It is also important to note that the optimised process conditions were constrained by the model assumptions, in particular, the maximum pressure was limited to 9 bar for the purpose of model validation. Several of the optimised parameters were also highly influenced by other parameters and therefore the results should not be extrapolated to other system configurations.

Table 2. Optimised TCMD process conditions

\begin{tabular}{ccc}
\hline Process Parameter & Value & Unit \\
\hline Temperature & 1223 & $\mathrm{~K}$ \\
Pressure & 9 & $\mathrm{bar}$ \\
Inlet gas mole fraction $\mathrm{CH}_{4}$ & 1 & - \\
Fluidisation velocity & 0.2522 & $\mathrm{~m} / \mathrm{s}$ \\
Catalyst particle size & 150 & $\mu \mathrm{m}$ \\
Relative catalyst activity limit & 0.22 & - \\
Catalyst mass & 1000 & $\mathrm{~kg}$ \\
Process Mode & isothermal & - \\
\hline
\end{tabular}




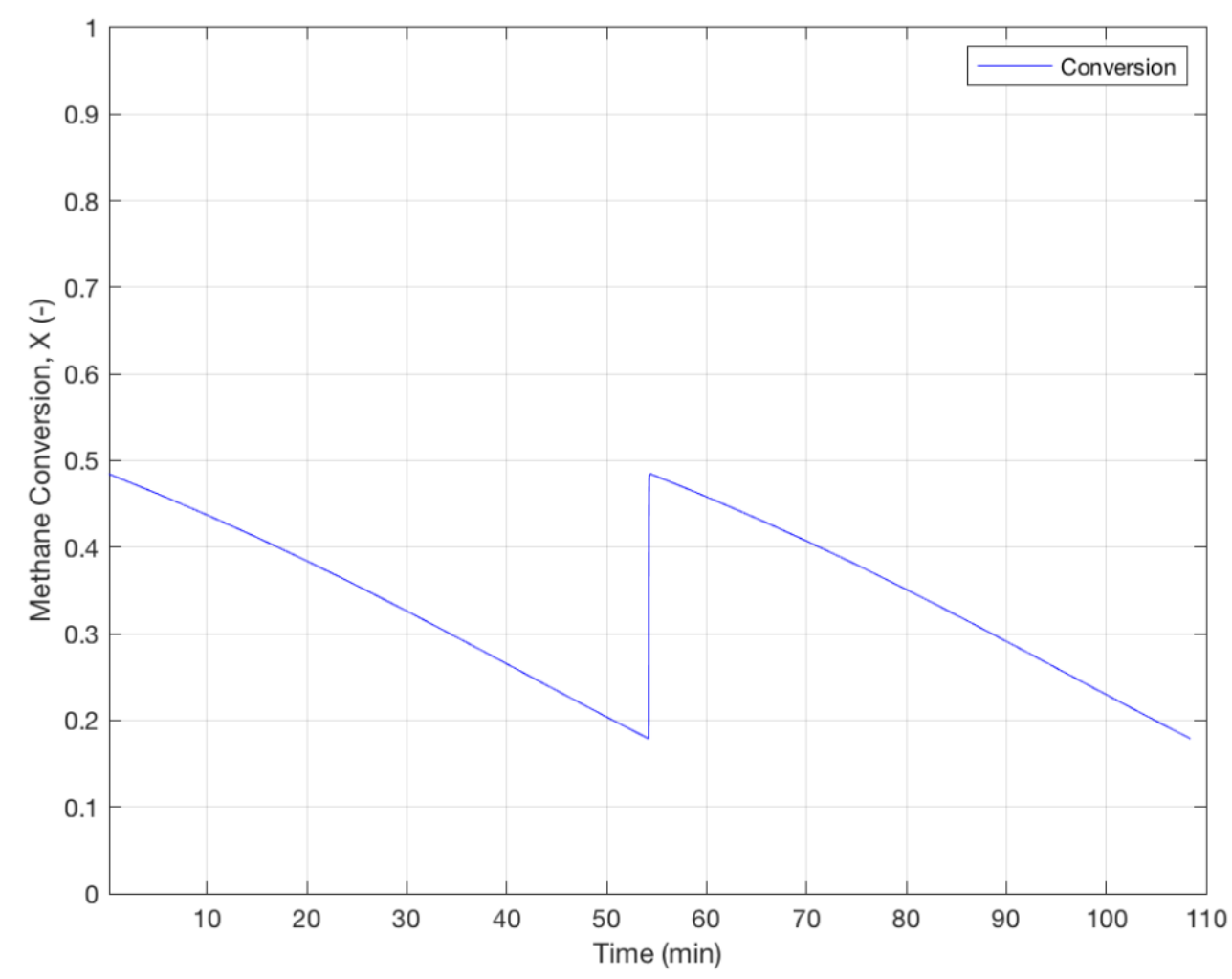

Figure 7. Deactivation behaviour for two catalyst cycles under the optimised TCMD process conditions $(T=$ $950 \circ \mathrm{C}, \mathrm{p}=9 \mathrm{bar}, \mathrm{SV}=5.4 \mathrm{~L} / \mathrm{g}$ cat $\mathrm{h}$ ).

\subsection{Parametric Study}

The following parametric study was conducted for a single catalyst cycle, with each parameter evaluated at the optimal operating conditions $\left(T=950^{\circ} \mathrm{C}, \mathrm{p}=9 \mathrm{bar}, \mathrm{SV}=5.4 \mathrm{~L} / \mathrm{g}\right.$ cat $\mathrm{h}$ ) except for the parameter undergoing sensitivity analysis.

\subsubsection{Temperature}

According to Le Chatelier's principle, a rise in the reaction temperature will favour higher conversion rates since the TCMD reaction is endothermic. However, through the use of an iron-based catalyst, the TCMD process has a stable temperature range of between approximately $700-950$ ㅇ $\mathrm{C}$ and increasing the temperature beyond this range results in catalyst sintering, which accelerates the rate of deactivation. The simulation results given in Figure 8 exhibits both of these trends with an optimal operating temperature just before the catalyst starts to sinter. It is clear from the graph that there is a growth in the hydrogen production rate as the temperature is increased, which appears to grow before turning linear at approximately $800^{\circ} \mathrm{C}$. Above the sintering limit of $950 \circ \mathrm{C}$, there is a slight decrease away from the linear behaviour, which indicates the hydrogen production rate is not strongly influenced by the increased deactivation rate due to sintering. The effect of sintering can be best observed via the catalyst turnover costs where the steady decline suddenly changes as the temperature transitions above $950^{\circ} \mathrm{C}$. Due to sintering, there is a significant rise in the deactivation rate, whereas below $950 \circ \mathrm{C}$ the increasing rate of deactivation associated with the rise in temperature does not negatively influence the catalyst turnover costs. This is due to the gain in the hydrogen yield, which outweighs the rate of deactivation via the fouling mechanism. 


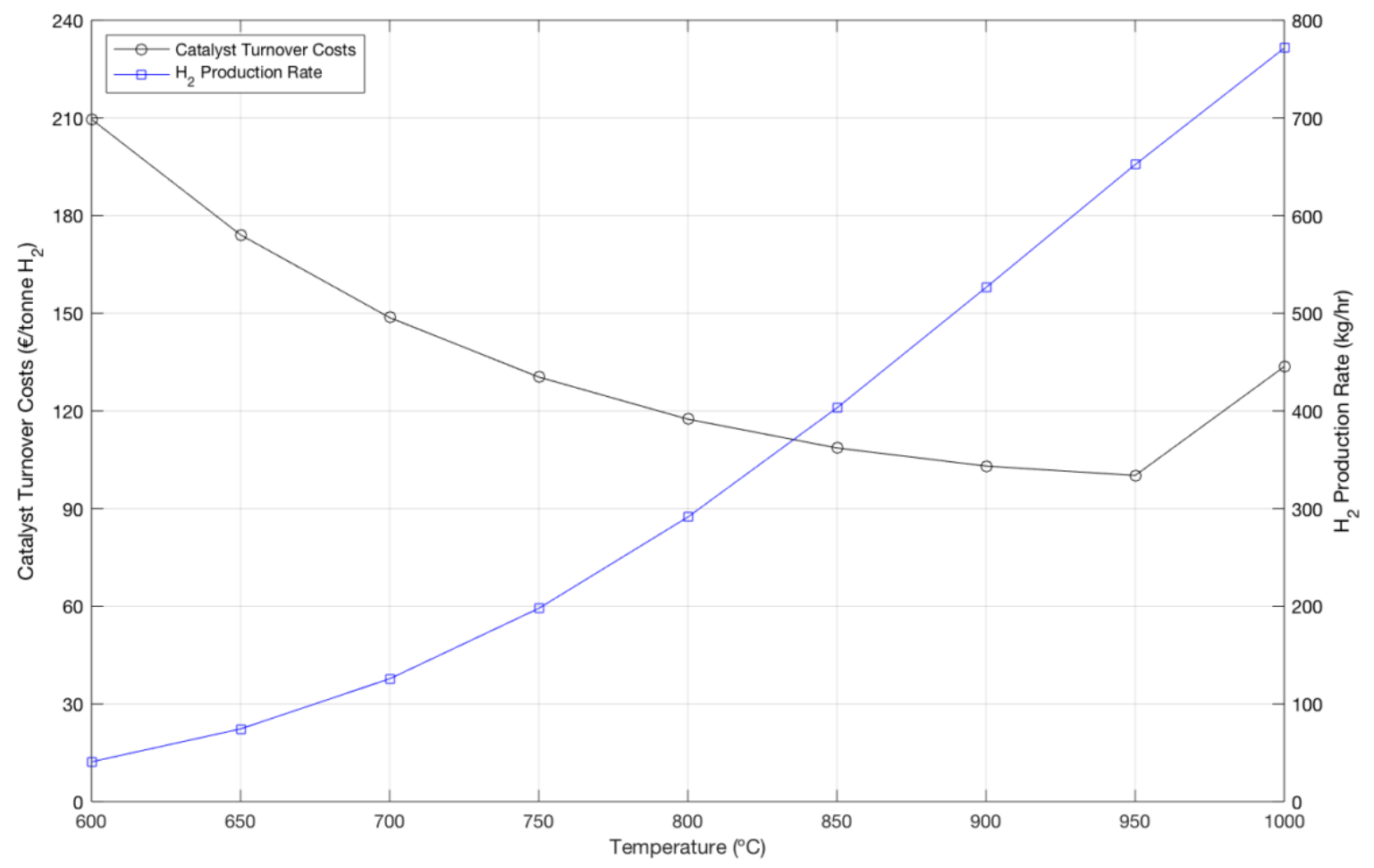

Figure 8. Influence of the reactor temperature ( $T=$ varied, $p=9$ bar, $S V=5.4 \mathrm{~L} / \mathrm{g}$ cat $\mathrm{h}$ ).

\subsubsection{Pressure}

The thermodynamics of the TCMD process dictates that an increase in pressure reduces the equilibrium conversion as the reaction shifts to the left. However, the concentration of the inlet gas is also influenced by the change in the pressure, since according to the ideal gas law which is applicable to low pressure gases, an increase in pressure is directly proportional to concentration - assuming constant temperature and reactor volume. By increasing the concentration and hence the molar flow rate of the inlet gas, more mass can enter the reactor and undergo the TCMD reaction, resulting in larger hydrogen production rates. Past researchers have attributed higher pressures to larger yields of hydrogen and experimental work conducted by Cornejo [6] claims that increasing the pressure also significantly lowers the catalyst turnover costs. To verify these claims, several simulation studies were performed with the results shown in Figure 9. By inspecting the graph, it is clear that by increasing the pressure, the economic potential of the process is maximised. When evaluated in the 1-9 bar pressure range given in this parametric study, the hydrogen production rate shows a proportionate increase with growing pressures mainly due to the direct influence of the total pressure on the mass flow rate of methane gas entering the reactor and undergoing the TCMD reaction. The influence of the reduced equilibrium conversion is not observed as the reaction is limited kinetically rather than thermodynamically due to the optimal process conditions and low pressures (1-9 bar) under which this parametric study was evaluated. The reduction in the equilibrium conversion from $99 \%$ at 1 bar to $91 \%$ at 9 bar for the operating temperature of $950 \% \mathrm{C}$ has no bearing effect on the hydrogen production rate under these optimal conditions since the reaction does not have sufficient time to reach equilibrium given the short residence time $(2.7 \mathrm{~s})$ in the reactor and is confined to the maximum kinetic conversion limit of $51 \%$ over the 1-9 bar pressure range. Therefore, the hydrogen production rate has an approximately linear increase with only a slight decrease associated with an increasing deactivation rate 
compared to the increase in reaction rate that is of negligible magnitude. The catalyst turnover costs, however, decrease exponentially with larger pressures, which confirm the claims made by Cornejo [6]. At higher pressures, the change in the turnover costs gradually reduces as the rate of deactivation becomes more dominant compared to the increased hydrogen yield, which results in more frequent catalyst cycles. Overall, the total pressure is considered a major operating variable for the optimisation of this process and should be maximised to the highest feasible pressure.

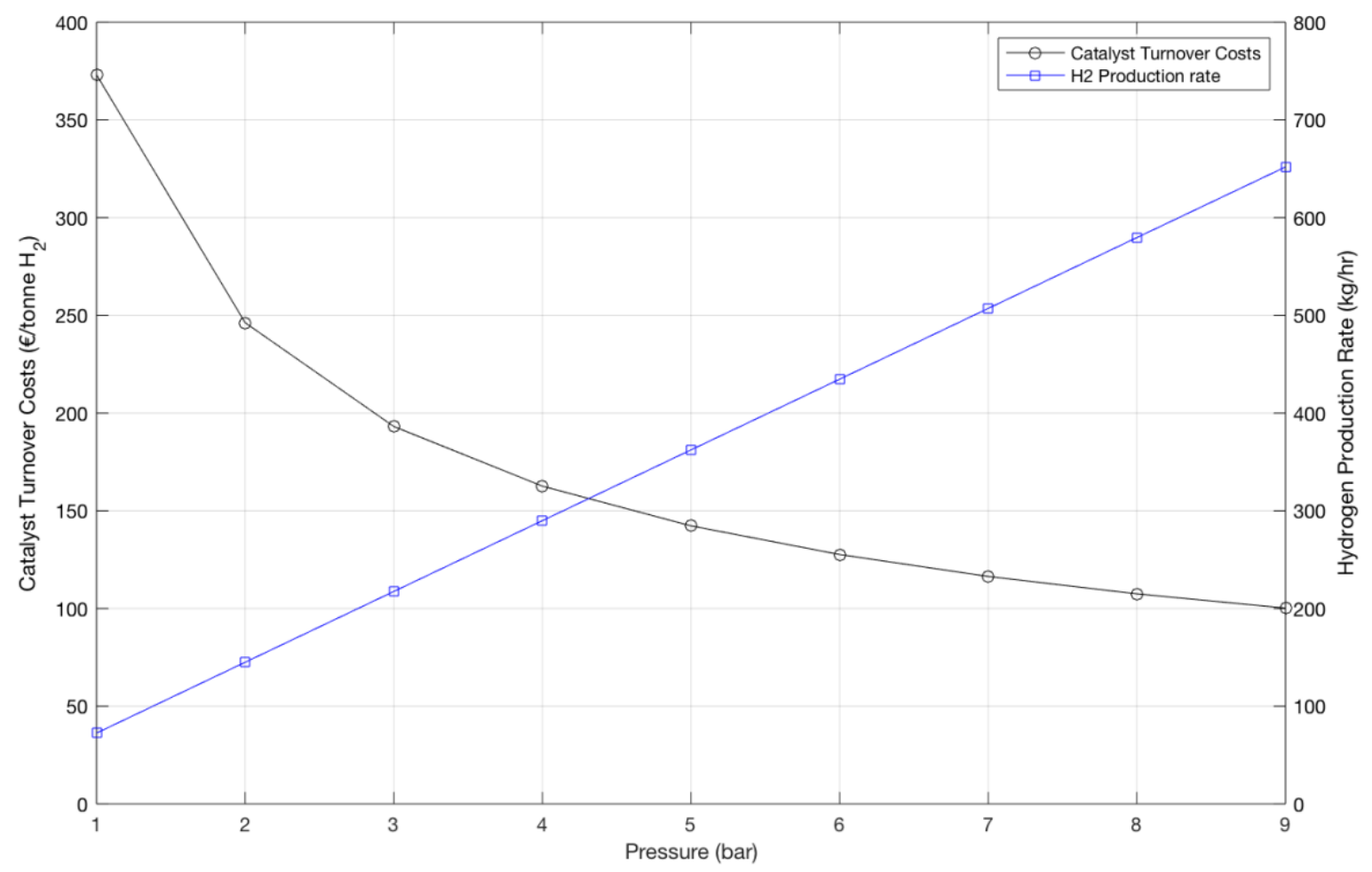

Figure 9. Influence of the reactor pressure $\left(T=950^{\circ} \mathrm{C}, \mathrm{p}=\right.$ varied, $\mathrm{SV}=5.4 \mathrm{~L} / \mathrm{g}$ cat $\left.\mathrm{h}\right)$.

\subsubsection{Inlet Gas Composition}

The adjustment of the inlet gas composition also has a direct effect on the methane and hydrogen partial pressures, which largely influence the TCMD process. Researchers have reported that the deactivation rate can be reduced by blending a portion of hydrogen into the inlet gas composition [31], [35]. Mathematically, this was modelled in the deactivation rate equation through the negative power constant for the hydrogen concentration term. Figure 10 shows that the hydrogen production rate increases linearly with an increase in the percentage of methane comprised in the inlet gas. The catalyst turnover costs, however, show an interesting behaviour with a gradual exponential reduction. The graph shows a clear optimal solution for maximising the economic potential of this process when the mole fraction of the inlet gas is composed entirely of methane. The reason for this is that more methane is able to enter the reactor and undergo decomposition despite the presence of hydrogen having a mitigating effect on catalyst deactivation. This mitigating effect causes a delay in the time taken for the catalyst to deactivate although this comes at a cost due to the reduction in the hydrogen production rate. Therefore, although blending hydrogen in the inlet gas reduces the deactivation rate and has been promoted by several researchers as a method to mitigate catalyst deactivation, it is economically unreasonable. 


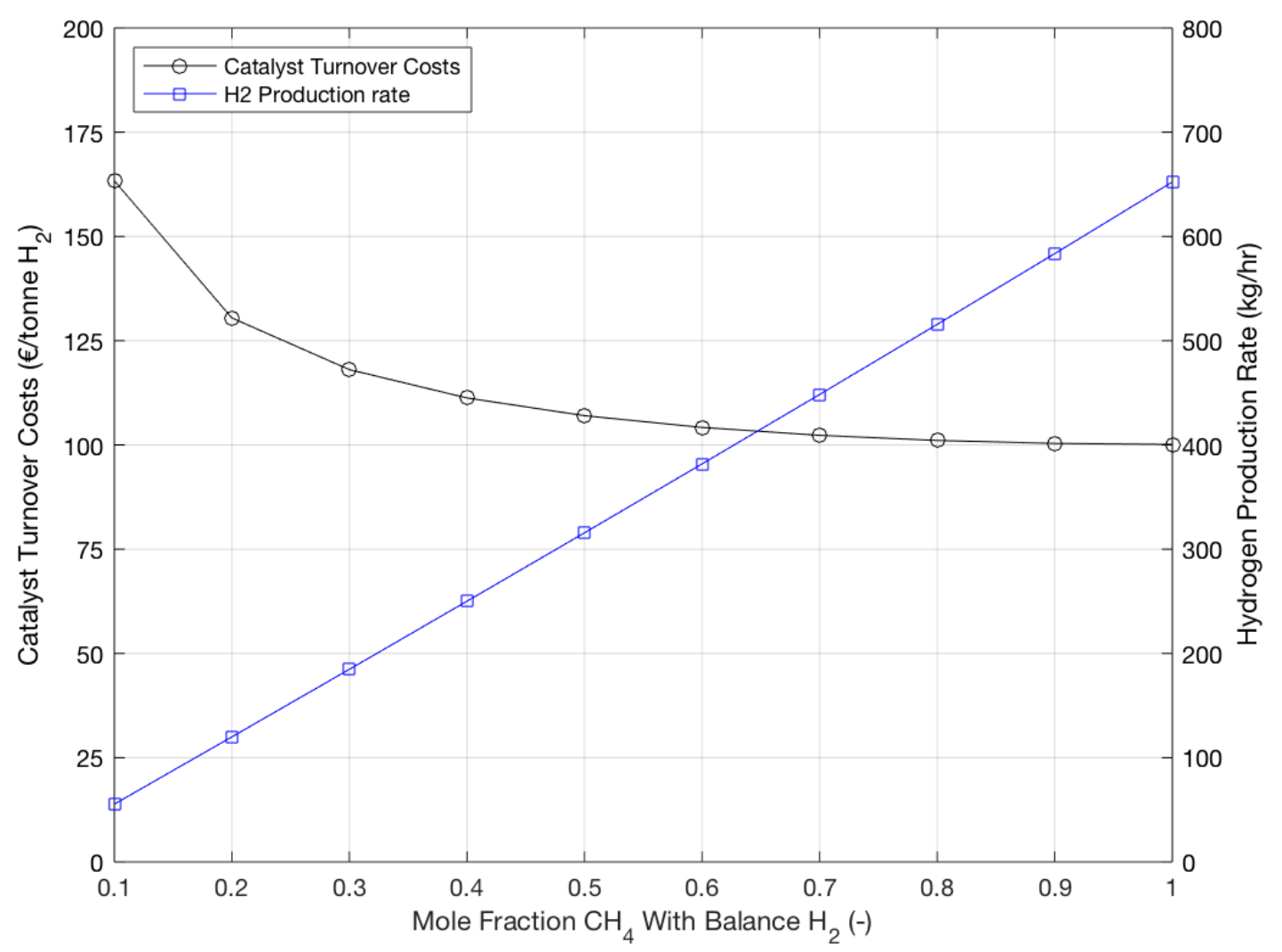

Figure 10. Influence of the inlet gas mole fraction $\left(T=950^{\circ} \mathrm{C}, \mathrm{p}=9\right.$ bar, $S V=5.4 \mathrm{~L} / \mathrm{g}$ cat $\left.\mathrm{h}\right)$.

\subsubsection{Fluidisation Velocity}

The fluidisation velocity has a crucial influence on the fluidising behaviour of the reactor. The most obvious effect for adjusting the fluidisation velocity is the change in the residence time of the gas in the reactor. This affects the maximum attainable conversion, as the reaction is limited kinetically at low pressures. Reducing the fluidisation velocity increases the residence time, allowing higher conversions as the reaction moves closer to the thermodynamic equilibrium limit. However, a disadvantage of reducing the fluidisation velocity is the reduction in the mass flow rate of methane, which decreases the hydrogen yield.

Figure 11 shows a sharp initial rise in the hydrogen production rate as the fluidisation velocity increases above the minimum fluidisation velocity. The significantly higher hydrogen yield is due to the large increase in the mass flow rate of methane with only a small negative effect on the conversion resulting from the lowered residence time and the presence of small bubbles. The hydrogen production rate then gradually eases to a maximum at $\mathrm{U}_{40 \%}$ of $814 \mathrm{~kg} / \mathrm{hr}$ before slowly decreasing to $720 \mathrm{~kg} / \mathrm{hr}$ at the terminal velocity. This decline can be attributed to the low residence times as well as the increased presence of bubbles, which further reduce the conversion rate. The catalyst turnover costs increase almost linearly with the exception of the catalyst turnover costs for minimum bubbling at $U_{10 \%}$. Due to the surge in the hydrogen production rate from $U_{m f}$ to $U_{10 \%}$, the turnover costs are reduced despite a rise in the catalyst deactivation rate. The higher deactivation rates due to the increased mass flow rate of methane entering the reactor is the main driver for the growing catalyst turnover costs for increasing fluidisation velocities. Using the optimisation ratio, the optimum fluidisation velocity for maximising the economic potential of the process was at $U_{10 \%}$. Numerous researchers have stated that a minimum bubbling regime is the most effective due to the enhanced gas-solid interactions [54], [55]. Through the results, it has also been shown that a minimum bubbling regime, such as $U_{10 \%}$, is ideal for this particular process economically as it allows for 
higher mass flow rates without a substantial decrease in the conversion.

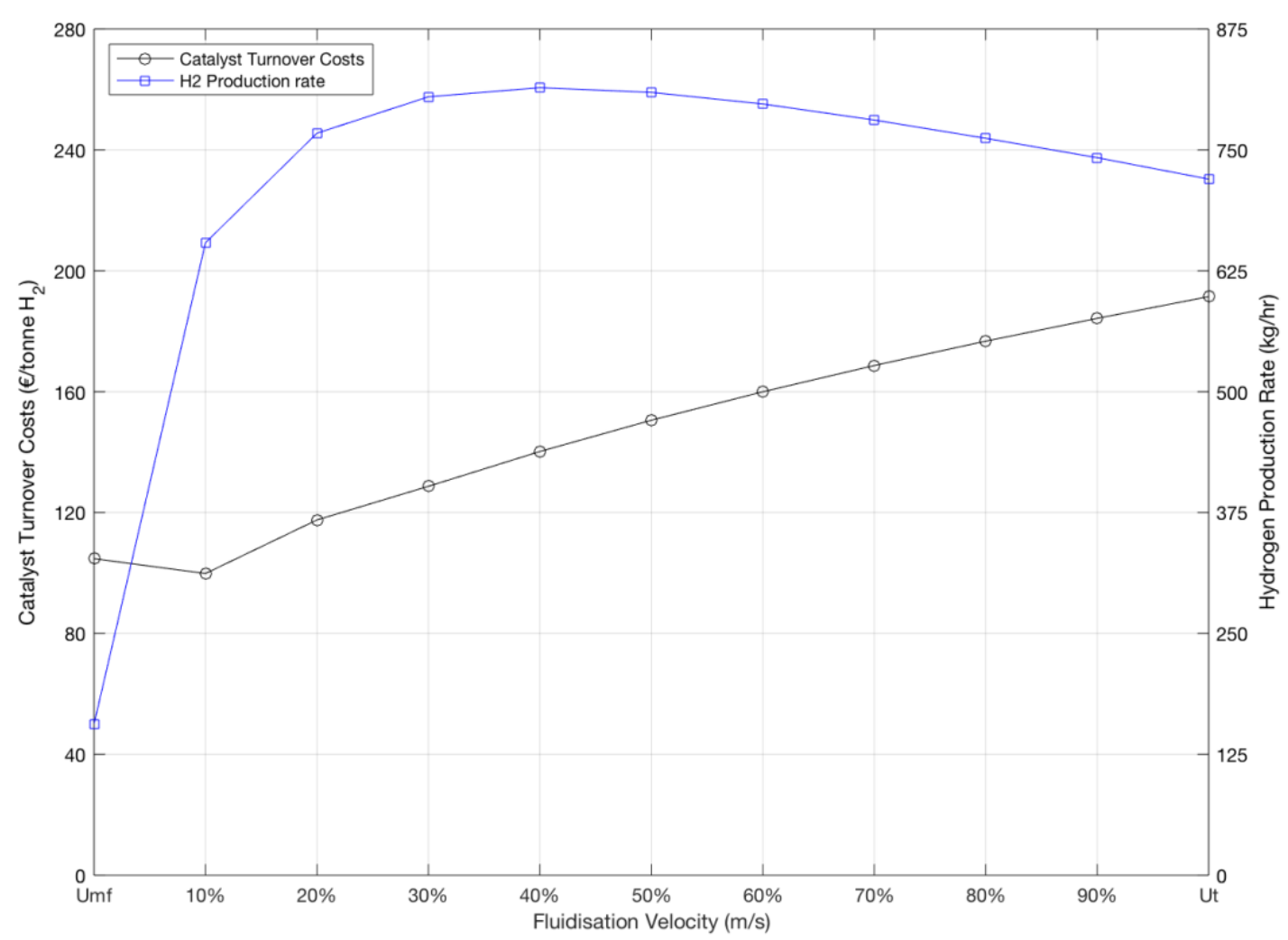

Figure 11. Influence of the fluidisation velocity $(T=950 \circ C, p=9$ bar, $S V=$ varied $)$.

\subsubsection{Catalyst Particle Size}

The size of the catalyst particle influences the dynamics of the fluidised bed as well as the range of fluidisation velocities that can be obtained. Increasing the catalyst particle size allows for higher inlet gas velocities to be reached due to the higher minimum fluidisation velocities required to suspend the heavier catalyst particles. Increasing the minimum fluidisation velocity enables a greater mass flow rate of methane and therefore output of hydrogen, with little adverse effects on the conversion due to the absence of bubbles. However, if a smaller catalyst particle were used at the same velocity, the conversion would be less due to the lower minimum fluidisation velocity and therefore the excess methane going unreacted in the bubbles. The effect of the catalyst particle size, within the range for Geldart A-type particles, on the catalyst turnover costs and hydrogen production rate can be seen in Figure 12 with each particle size simulated at their minimum fluidisation velocity.

Inspecting the graph, there is a clear optimum solution for maximising the hydrogen production rate and minimising the catalyst turnover costs as initially indicated. Through the use of larger catalyst particle sizes, greater hydrogen production rates can be achieved with minimal negative effects on the conversion. This translates to lower turnover costs for increasing catalyst particle sizes, although a maximum of $150 \mu \mathrm{m}$ was defined to keep within the Geldart A-type catalyst particle size classification for smooth fluidising behaviour. 


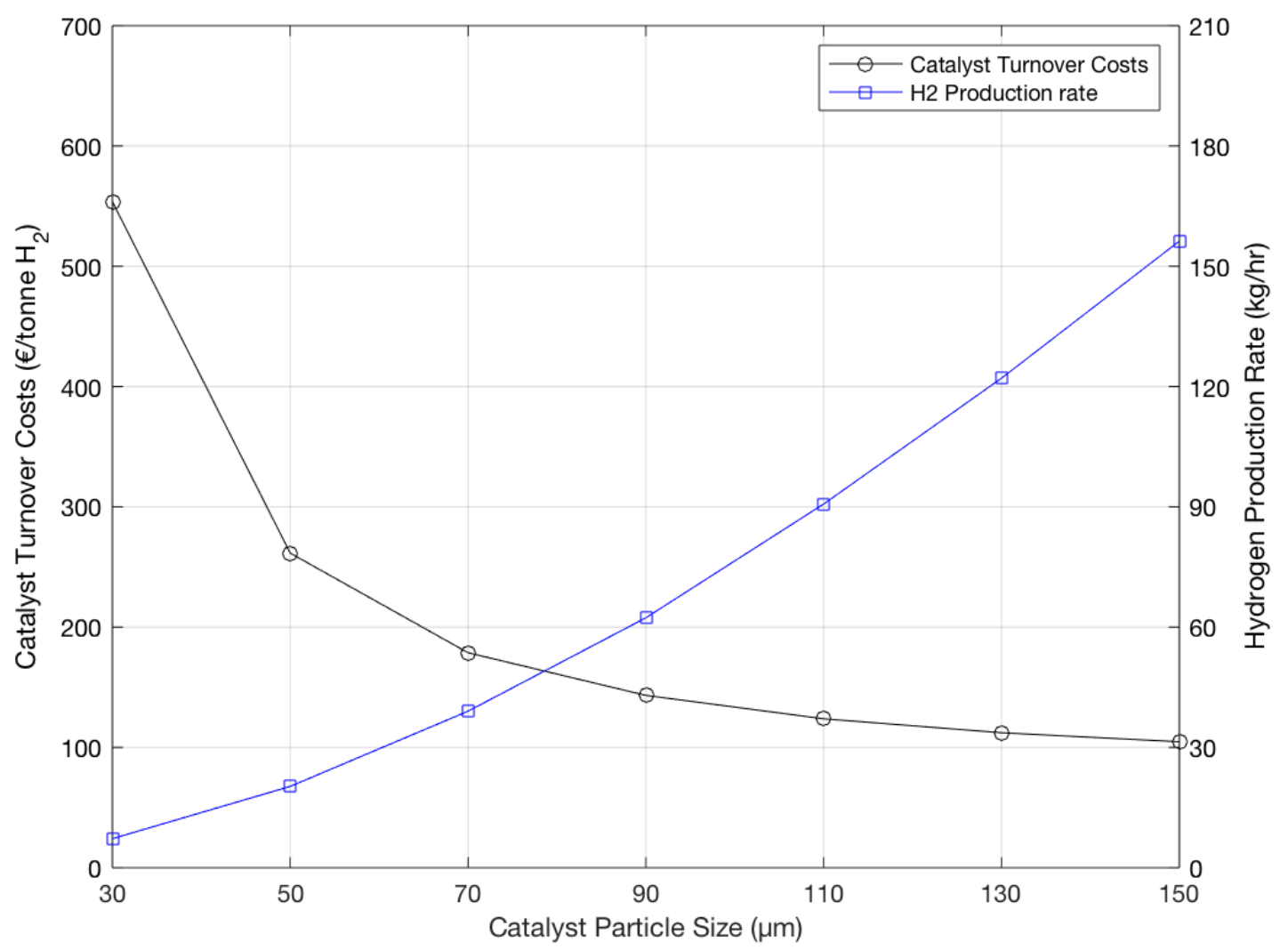

Figure 12. Influence of the catalyst particle size $(T=950 \circ \mathrm{C}, \mathrm{p}=9 \mathrm{bar}, \mathrm{SV}=5.4 \mathrm{~L} / \mathrm{g}$ cat $\mathrm{h})$.

\subsubsection{Catalyst Activity Limit}

The catalyst activity limit dictates the point at which the deactivating catalyst should be removed and fresh catalyst inserted. In previous studies, the catalyst was always replaced once it had fully deactivated and never prior. However, this may not be the most optimum solution for maximising the economic potential of the process since the time taken towards the end of the catalyst life is much longer than the initial life of the catalyst and this results in lower average conversion rates due to the prolonged exposure to reduced catalytic activity. By increasing the catalyst activity limit, greater conversion rates can be experienced for a longer period of time, which translates to higher yields of hydrogen. However, a disadvantage of this adjustment is the increased number of catalyst cycles, which increases the catalyst turnover costs. The exact effect of adjusting this variable on the catalyst turnover costs and the production rate of hydrogen is unknown and the ideal point at which the catalyst should be cycled should be determined.

The results from Figure 13 show an initial increase in the hydrogen production rate, which then slowed as it approached the hydrogen production limit at $100 \%$ catalyst activity. This reduced gain in the hydrogen yield had an influence on the catalyst turnover costs, together with the increasing number of catalyst cycles, which caused the catalyst turnover costs to grow exponentially. The optimum solution was found to be at the catalyst activity limit of $22 \%$ using the optimisation ratio. It was found that the hydrogen production rate had a crucial influence on the activity limit. At the model base conditions, where the hydrogen yield is comparatively small, the gain in the hydrogen production rate due to increasing the activity limit did not outweigh the added number of catalyst cycles and so the optimum activity limit stayed at the steady-state activity limit. This shows that the optimum activity limit strongly depends on the other process conditions and the optimum can be computed through model-based optimisation. 


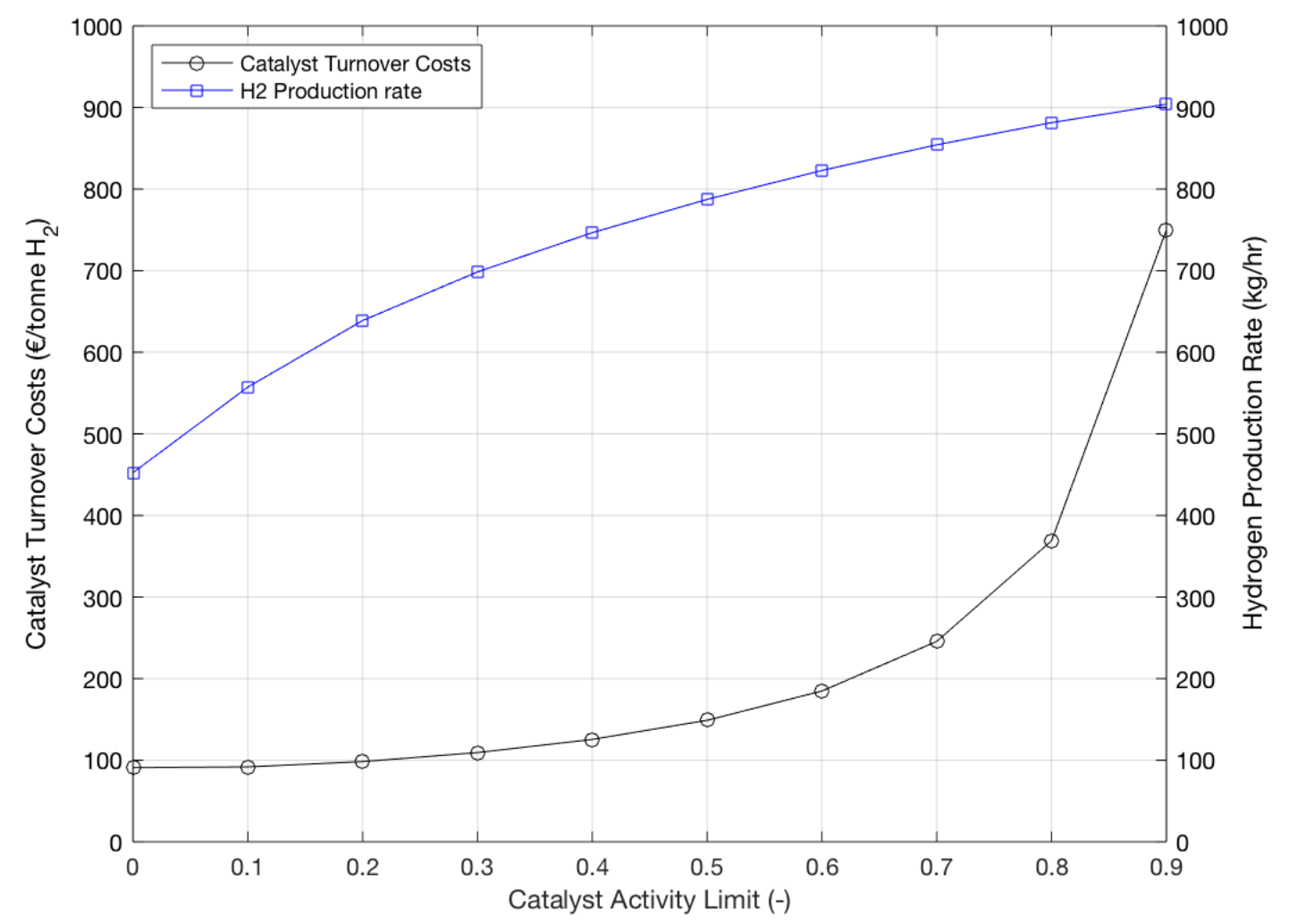

Figure 13. Influence of the catalyst activity limit ( $T=950 \circ \mathrm{C}, p=9$ bar, $S V=5.4 \mathrm{~L} / \mathrm{g}$ cat $h$ ).

\subsubsection{Process Mode}

The effect of the different process modes on the TCMD process has received little attention compared to the vast amounts of research conducted on the different heat sources available for the process. Due to the endothermic nature of the reaction and the phenomenon of catalyst deactivation, the process mode is of particular interest as a parameter that can be manipulated to optimise the production of hydrogen and lower the catalyst turnover costs.

As previously discussed, as the catalyst deactivates, the conversion is typically decreased but depending on the level of heat input and chosen process mode, the methane conversion can be adjusted. The "medium" level of heat input was chosen for the constant heating process mode as it enabled a relatively stable conversion without reaching excessive reaction temperatures. A comparison of the four process modes was conducted through several simulation studies with the methane conversion and temperature profiles shown in Figure 14Figure 14. Influence of the process mode on the methane conversion and reaction temperature for a single catalyst cycle (initial conditions: $\mathrm{T}=950^{\circ} \mathrm{C}, \mathrm{p}=9 \mathrm{bar}, \mathrm{SV}=5.4 \mathrm{~L} / \mathrm{g}$ cat $\mathrm{h}$ ). and the quantified reaction pathways given in Figure 15. The results for the catalyst turnover cost and the hydrogen production rates are given in Table 3 for a single catalyst cycle at the optimal operating conditions. It is important to note that the adiabatic process mode was omitted in the tabulated results since the reaction quickly extinguished and therefore the sharp drop in conversion should not be attributed to the deactivation of the catalyst. 

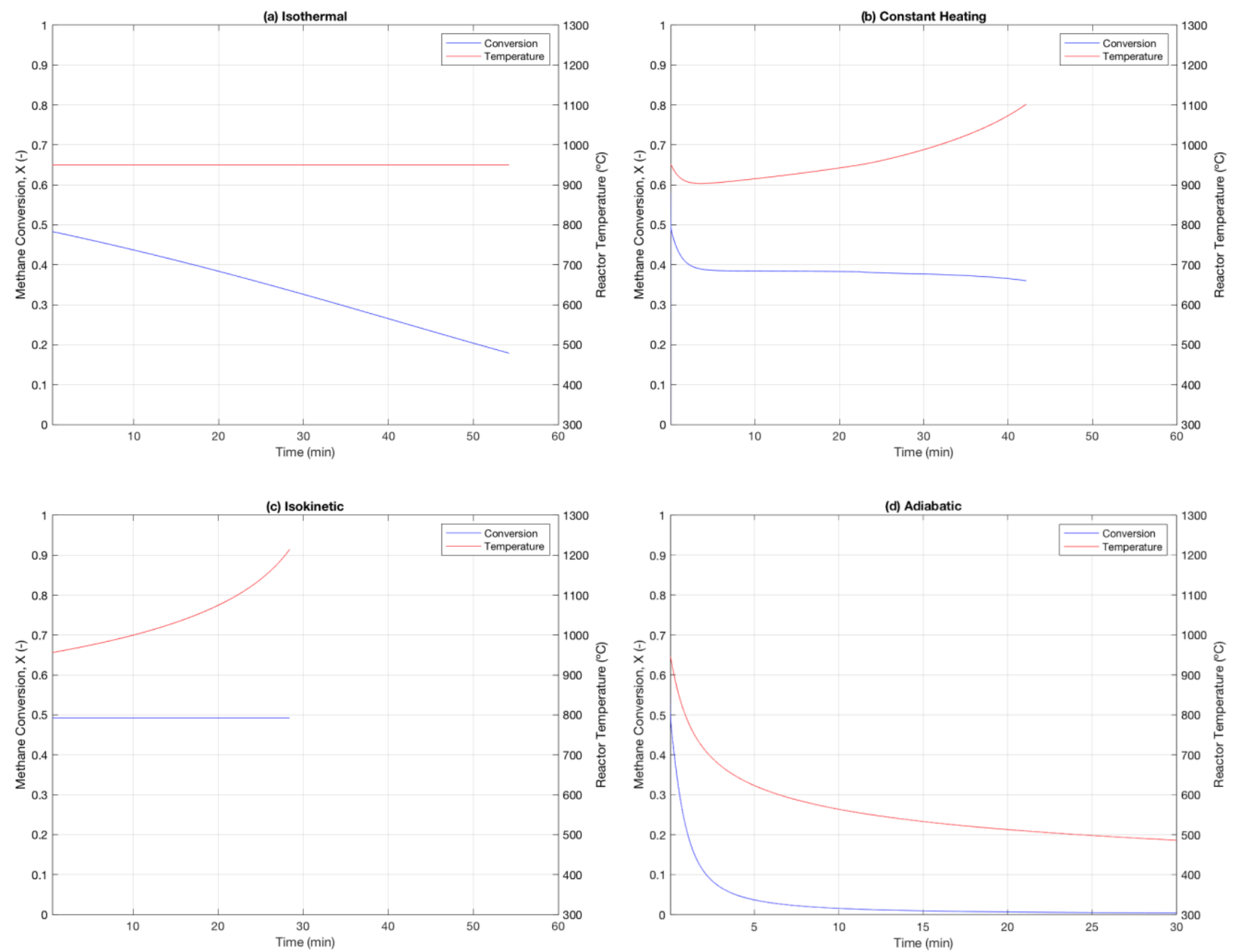

Figure 14. Influence of the process mode on the methane conversion and reaction temperature for a single catalyst cycle (initial conditions: $T=950 \circ \mathrm{C}, \mathrm{p}=9 \mathrm{bar}, \mathrm{SV}=5.4 \mathrm{~L} / \mathrm{g}$ cat $\mathrm{h}$ ). 


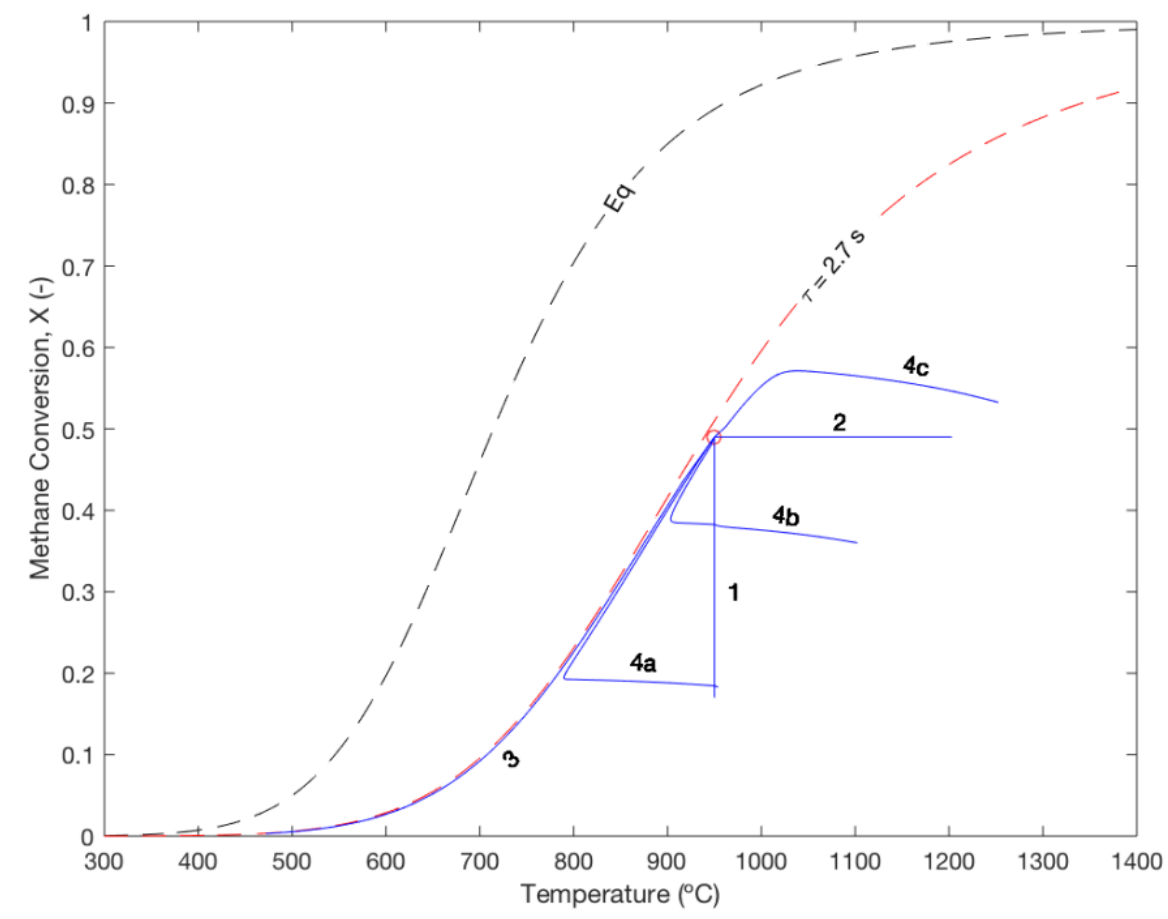

Figure 15. Quantitative reaction pathways for 1 ) isothermal, 2) isokinetic, 3) adiabatic and 4) constant heating [a) low, b) medium, c) high]. (initial conditions: $T=950 \circ \mathrm{C}, \mathrm{p}=9$ bar, $S V=5.4 \mathrm{~L} / \mathrm{g}$ cat $\mathrm{h}$ ).

Table 3. Hydrogen production rate and turnover cost results for various TCMD process modes

\begin{tabular}{ccc}
\hline Process Mode & Hydrogen Production Rate $(\mathrm{kg} / \mathrm{hr})$ & $\begin{array}{c}\text { Catalyst Turnover Costs } \\
\left(€ / \text { tonne } \mathrm{H}_{2}\right)\end{array}$ \\
\hline $\begin{array}{c}\text { Isothermal } \\
\begin{array}{c}\text { Constant Heating } \\
\text { (Medium) }\end{array}\end{array}$ & 652.14 & 100.17 \\
Isokinetic & 735.88 & 112.56 \\
\hline
\end{tabular}

The results for the methane conversion and temperature profiles for the different process modes differ greatly and have a large effect on the economic potential of the process. During the constant heating and isokinetic process modes, the hydrogen production rate is increased compared to the isothermal mode as the methane conversion sustains at a relatively stable level. This is due to the excess heat input during deactivation, which results in a temperature gain and a subsequent increase in the reaction rate. However, as the catalyst deactivates, the increased reaction temperature, which elevates above the sintering limit, causes an increased catalyst deactivation rate despite the sustained conversion. This results in a shorter cycle time and therefore a higher catalyst turnover cost.

From the results displayed in Table 3, both the constant heating and isokinetic process modes are more economically attractive than the preferred isothermal process mode, which is extensively used in the research literature. The constant heating process mode is slightly more cost-efficient than the isothermal process mode, however, the isokinetic process mode is much more economically attractive with a $45 \%$ increase in the hydrogen production rate and only a $30 \%$ increase in the catalyst turnover costs. It is important to note that the added heat costs and the effect of sintering on the graphitic carbon by-product, which could reduce its value, are not considered. The carbon by-product is considered a key variable in the commercial feasibility of this process and 
therefore any loss of revenue could inhibit its commercial adoption. For this reason, the isothermal process mode was found to be better suited for the TCMD process due to its thermal stability although, further research into the sintering effects of the carbon by-product should be carried out to determine if the constant heating and isokinetic process modes could be implemented.

\section{Conclusion}

The production of turquoise hydrogen from the TCMD process can be considered a suitable intermediate solution that can empower the energy transition, although this process is yet to be commercialised partly due to the high catalyst turnover costs resulting from the deactivation of the catalyst. The model developed in this work allows for a basic feasibility analysis and optimisation of the TCMD process conditions to maximise the hydrogen yield, whilst minimising the catalyst turnover costs. Through the parametric study carried out over numerous numerical simulations, a number of general conclusions can be made regarding the operating conditions and their effect on the economic potential of the process.

- The operating temperature should be maximised but remain below the sintering temperature of the catalyst.

- The reactor pressure should be maximised to the highest feasible pressure.

- It is economically unreasonable to blend hydrogen in the inlet gas to reduce the catalyst deactivation rate.

- The catalyst particle size should be maximised but remain within the Geldart Type-A limit for smooth fluidisation.

- The fluidisation velocity should remain in the minimum fluidisation to minimum bubbling flow regimes to promote enhanced gas-solid interactions and reduce the presence of large bubbles.

- The amount of catalyst in the reactor should be maximised to reduce the frequency of catalyst cycles but not inhibit the fluidisation properties of the catalyst bed.

- The process should be operated isothermally to ensure thermal stability, although different heating strategies such as constant heating and isokinetic operation enable higher conversion rates and should be further investigated to understand the impact of elevated temperatures on the carbon by-product.

General recommendations for the optimal catalyst activity limit cannot be given as this parameter is heavily dependent on the other operating conditions of the process and can only be found through simulation analysis. From this study, it has been shown that by conducting a parametric optimisation of the TCMD process, through an appropriate model, the economic potential of the process can be maximised. It is important to evaluate innovative processes such as the TCMD process at their optimal operating conditions in order to accurately determine their commercial viability and costs in comparison to other potential processes. Such an evaluation would prevent the TCMD process from being simply dismissed as a viable emission reduction pathway for hydrogen production. In addition, by better enabling the feasibility analysis and process design of the TCMD process, its uptake in the industry can be increased, which could significantly reduce GHG emissions in the short term when compared to current methods of hydrogen production and could contribute to the emission reductions required to achieve the targets set out in the Paris Agreement.

Recommendations for future research on modelling of the TCMD process should focus on reducing the number of constraints in order to model the process closer to the real system. The present model was limited by several assumptions due to scope of study, which influenced the results; most notably the single reactor configuration, maximum pressure of 9 bar and the sharp temperature for when the catalyst starts to sinter. Future work should be conducted to extend the model scope, including investigations into multi-step systems with varying pressure levels as well as further experimental work on the kinetics of catalyst deactivation for $\mathrm{Fe}_{2} \mathrm{O}_{3}$ catalysts. 


\section{Conflicts of Interest}

The authors declare no conflicts of interest regarding the publication of this paper.

\section{References}

[1] International Energy Agency. The Future of Hydrogen: Seizing today's opportunities. Paris: 2019.

[2] Gürsan C, de Gooyert V. The systemic impact of a transition fuel: Does natural gas help or hinder the energy transition? Renewable and Sustainable Energy Reviews 2021;138. https://doi.org/10.1016/j.rser.2020.110552.

[3] Mayyas A, Wei M, Levis G. Hydrogen as a long-term, large-scale energy storage solution when coupled with renewable energy sources or grids with dynamic electricity pricing schemes. International Journal of Hydrogen Energy 2020;45. https://doi.org/10.1016/j.ijhydene.2020.04.163.

[4] Parkinson B, Tabatabaei M, Upham DC, Ballinger B, Greig C, Smart S, et al. Hydrogen production using methane: Techno-economics of decarbonizing fuels and chemicals. International Journal of Hydrogen Energy 2018;43. https://doi.org/10.1016/i.ijhydene.2017.12.081.

[5] Raza A, Gholami R, Rezaee R, Rasouli V, Rabiei M. Significant aspects of carbon capture and storage - A review. Petroleum 2019;5. https://doi.org/10.1016/j.pet/m.2018.12.007.

[6] Cornejo A. The Thermo-Catalytic Decomposition of Methane for Economical and Emission-Free Hydrogen Production. Ph.D. Thesis. University of Western Australia, 2013.

[7] Howarth RW, Jacobson MZ. How green is blue hydrogen? Energy Science \& Engineering 2021;9. https://doi.org/10.1002/ese3.956.

[8] Steinberg M. Fossil fuel decarbonization technology for mitigating global warming. International Journal of Hydrogen Energy 1999;24. https://doi.org/10.1016/S0360-3199(98)00128-1.

[9] Dufour J, Serrano D, Gálvez J, Moreno J, García C. Life cycle assessment of processes for hydrogen production. Environmental feasibility and reduction of greenhouse gases emissions. International Journal of Hydrogen Energy 2009;34. https://doi.org/10.1016/j.ijhydene.2008.11.053.

[10] Abbas HF, Wan Daud WMA. Hydrogen production by methane decomposition: A review. International Journal of Hydrogen Energy 2010;35. https://doi.org/10.1016/j.ijhydene.2009.11.036.

[11] Weger L, Abánades A, Butler T. Methane cracking as a bridge technology to the hydrogen economy. International Journal of Hydrogen Energy 2017;42. https://doi.org/10.1016/i.ijhydene.2016.11.029.

[12] Srilatha K, Bhagawan D, Shiva Kumar S, Himabindu V. Sustainable fuel production by thermocatalytic decomposition of methane - A review. South African Journal of Chemical Engineering 2017;24. https://doi.org/10.1016/j.sajce.2017.10.002.

[13] Munera Parra AA, Platte F, Agar DW. Multiplicity Regions in a Moving-Bed Reactor: Bifurcation Analysis, Model Extension, and Application for the High-Temperature Pyrolysis of Methane. Chemie Ingenieur Technik 2016;88. https://doi.org/10.1002/cite.201600069.

[14] Pinilla JL, de Llobet S, Moliner R, Suelves I. H2 -rich gases production from Catalytic Decomposition of Biogas: Viability of the process associated to the co-production of carbon nanofibers. International Journal of Hydrogen Energy 2017;42. https://doi.org/10.1016/i.ijhydene.2017.01.119.

[15] Qian JX, Chen TW, Enakonda LR, Liu D bin, Mignani G, Basset J-M, et al. Methane decomposition to produce COx-free hydrogen and nano-carbon over metal catalysts: A review. International Journal of Hydrogen Energy 2020;45. https://doi.org/10.1016/j.ijhydene.2020.01.052. 
[16] Qian JX, Enakonda LR, Wang WJ, Gary D, Del-Gallo P, Basset J-M, et al. Optimization of a fluidized bed reactor for methane decomposition over Fe/Al2O3 catalysts: Activity and regeneration studies. International Journal of Hydrogen Energy 2019;44. https://doi.org/10.1016/i.ijhydene.2019.10.058.

[17] Shah N, Ma S, Wang Y, Huffman GP. Semi-continuous hydrogen production from catalytic methane decomposition using a fluidized-bed reactor. International Journal of Hydrogen Energy 2007;32. https://doi.org/10.1016/j.ijhydene.2007.04.040.

[18] Keipi T. Technology Development and Techno-Economic Analysis of Hydrogen Production by Thermal Decomposition of Methane. Ph.D. Thesis. Tampere University of Technology. 2017.

[19] Wang J, Jin L, Li Y, Wang M, Hu H. Effect of hydrogen additive on methane decomposition to hydrogen and carbon over activated carbon catalyst. International Journal of Hydrogen Energy 2018;43. https://doi.org/10.1016/j.ijhydene.2018.07.179.

[20] Domínguez A, Fidalgo B, Fernández Y, Pis J, Menéndez J. Microwave-assisted catalytic decomposition of methane over activated carbon for $\mathrm{CO} 2 \mathrm{CO}$-free hydrogen production. International Journal of Hydrogen Energy 2007;32. https://doi.org/10.1016/i.ijhydene.2007.07.041.

[21] Amin AM, Croiset E, Epling W. Review of methane catalytic cracking for hydrogen production. International Journal of Hydrogen Energy 2011;36. https://doi.org/10.1016/j.ijhydene.2010.11.035.

[22] Riley J, Atallah C, Siriwardane R, Stevens R. Technoeconomic analysis for hydrogen and carbon CoProduction via catalytic pyrolysis of methane. International Journal of Hydrogen Energy 2021;46. https://doi.org/10.1016/j.ijhydene.2021.03.151.

[23] Muradov N. Thermocatalytic CO2-Free Production of Hydrogen from Hydrocarbon Fuels. University of Central Florida. UFC Patents 594, 2003. https://stars.library.ucf.edu/patents/594.

[24] Caballero M, del Angel G, Bonilla-Sánchez A, Rangel-Vázquez I, Arrieta A, Vázquez-Zavala A, et al. High selectivity to hydrogen on the methane decomposition over $\mathrm{Rh} / \mathrm{\gamma}-\mathrm{Al} 2 \mathrm{O} 3-\mathrm{Nd} 2 \mathrm{O} 3$ catalysts. International Journal of Hydrogen Energy 2016;41. https://doi.org/10.1016/j.ijhydene.2016.10.001.

[25] Ashik UPM, Wan Daud WMA, Abbas HF. Production of greenhouse gas free hydrogen by thermocatalytic decomposition of methane - A review. Renewable and Sustainable Energy Reviews 2015;44. https://doi.org/10.1016/i.rser.2014.12.025.

[26] Frusteri F, Italiano G, Espro C, Cannilla C, Bonura G. H2 production by methane decomposition: Catalytic and technological aspects. International Journal of Hydrogen Energy 2012;37. https://doi.org/10.1016/ji.ijhydene.2012.02.192.

[27] Torres D, de Llobet S, Pinilla JL, Lázaro MJ, Suelves I, Moliner R. Hydrogen production by catalytic decomposition of methane using a Fe-based catalyst in a fluidized bed reactor. Journal of Natural Gas Chemistry 2012;21. https://doi.org/10.1016/S1003-9953(11)60378-2.

[28] Zhou L, Enakonda LR, Harb M, Saih Y, Aguilar-Tapia A, Ould-Chikh S, et al. Fe catalysts for methane decomposition to produce hydrogen and carbon nano materials. Applied Catalysis B: Environmental 2017;208. https://doi.org/10.1016/i.apcatb.2017.02.052.

[29] Qian JX, Chen TW, Enakonda LR, Liu D bin, Basset J-M, Zhou L. Methane decomposition to pure hydrogen and carbon nano materials: State-of-the-art and future perspectives. International Journal of Hydrogen Energy 2020;45. https://doi.org/10.1016/j.ijhydene.2020.04.100.

[30] Alves Silva J, Oliveira Santos JB, Torres D, Pinilla JL, Suelves I. Natural Fe-based catalysts for the production of hydrogen and carbon nanomaterials via methane decomposition. International Journal of Hydrogen Energy 2021;46. https://doi.org/10.1016/j.ijhydene.2021.08.065. 
[31] Villacampa JI, Royo C, Romeo E, Montoya JA, del Angel P, Monzón A. Catalytic decomposition of methane over Ni-Al2O3 coprecipitated catalysts. Applied Catalysis A: General 2003;252.

https://doi.org/10.1016/S0926-860X(03)00492-7.

[32] Pinilla JL, Utrilla R, Karn RK, Suelves I, Lázaro MJ, Moliner R, et al. High temperature iron-based catalysts for hydrogen and nanostructured carbon production by methane decomposition. International Journal of Hydrogen Energy 2011;36. https://doi.org/10.1016/i.ijhydene.2011.01.184.

[33] Fogler H. Elements of Chemical Reaction Engineering: 5th Edition. Prentice Hall; 2016.

[34] Sánchez-Bastardo N, Schlögl R, Ruland H. Methane Pyrolysis for CO2-Free H2 Production: A Green Process to Overcome Renewable Energies Unsteadiness. Chemie Ingenieur Technik 2020;92. https://doi.org/10.1002/cite.202000029.

[35] Amin A. Modeling and Experimental Study of Methane Catalytic Cracking as a Hydrogen Production Technology. Ph.D. Thesis. University of Waterloo. 2011.

[36] Naresh G. Design and Development of Nickel Based Catalysts for COx Free H2 Production by Catalytic Decomposition of Methane. M.Sc. Thesis. RMIT University. 2017.

[37] Grabke H. Evidence on the Surface Concentration of Carbon on Gamma Iron from the Kinetics of the Carburization in CH4-H2. Metallurgical Transactions 1970;1:2972-5.

[38] Fager-Pintila M. Thermocatalytic Decomposition of Methane. M.Sc. Thesis. Tampere University of Technology. 2012.

[39] Toncu DC, Toncu G, Soleimani S. On methane pyrolysis special applications. IOP Conference Series: Materials Science and Engineering 2015;95. https://doi.org/10.1088/1757-899X/95/1/012026.

[40] Sharif Zein SH, Mohamed AR, Talpa Sai PS. Kinetic Studies on Catalytic Decomposition of Methane to Hydrogen and Carbon over Ni/TiO ${ }_{2}$ Catalyst. Industrial \& Engineering Chemistry Research 2004;43. https://doi.org/10.1021/ie034208f.

[41] Rodat S, Abanades S, Coulié J, Flamant G. Kinetic modelling of methane decomposition in a tubular solar reactor. Chemical Engineering Journal 2009;146. https://doi.org/10.1016/j.cej.2008.09.008.

[42] Zhou L, Enakonda LR, Li S, Gary D, Del-Gallo P, Mennemann C, et al. Iron ore catalysts for methane decomposition to make COx free hydrogen and carbon nano material. Journal of the Taiwan Institute of Chemical Engineers 2018;87. https://doi.org/10.1016/i.jtice.2018.03.008.

[43] Larsson A. Study of Catalyst Deactivation in Three Different Industrial Processes. Ph.D. Thesis. Växjö University. 2007.

[44] Argyle M, Bartholomew C. Heterogeneous Catalyst Deactivation and Regeneration: A Review. Catalysts 2015;5. https://doi.org/10.3390/catal5010145.

[45] Suelves I, Lázaro M, Moliner R, Corbella B, Palcios J. Hydrogen production by thermo catalytic decomposition of methane on Ni-based catalysts: influence of operating conditions on catalyst deactivation and carbon characteristics. International Journal of Hydrogen Energy 2005;30. https://doi.org/10.1016/i.ijhydene.2004.10.006.

[46] Chen Q, Lua AC. Kinetic reaction and deactivation studies on thermocatalytic decomposition of methane by electroless nickel plating catalyst. Chemical Engineering Journal 2020;389. https://doi.org/10.1016/j.cej.2020.124366.

[47] Baerns M. Aspects of Heterogeneous Catalysis and of Its Industrial and Environmental Practice. Reference Module in Chemistry, Molecular Sciences and Chemical Engineering, Elsevier; 2014. https://doi.org/10.1016/B978-0-12-409547-2.11041-8.

[48] Al-Fatesh A, Amin A, Ibrahim A, Khan W, Soliman M, AL-Otaibi R, et al. Effect of Ce and Co Addition to $\mathrm{Fe} / \mathrm{Al} 2 \mathrm{O} 3$ for Catalytic Methane Decomposition. Catalysts 2016;6. https://doi.org/10.3390/catal6030040. 
[49] Wen C, Yu Y. Mechanics of Fluidization. Chemical Engineering Progress Symposium Series 1966;62:10011.

[50] Grace JR. Contacting modes and behaviour classification of gas-solid and other two-phase suspensions. The Canadian Journal of Chemical Engineering 1986;64. https://doi.org/10.1002/cjce.5450640301.

[51] Business Insider. Commodities: Iron Ore Price Spot Price Chart 2020. https://markets.businessinsider.com/commodities/iron-ore-price.

[52] Basset J, Zhou L, Enakonda L. Treated Iron Ore Catalysts for Production of Hydrogen and Graphene. International Patent No. WO2018/189723 Al, 2018.

[53] Basset J, Zhou L, Saih Y, Enakonda L. Supported Iron Catalysts, Methods of Making, Methods of Hydrocarbon Decomposition. US Patent No. 2016/0129423 A1, 2016.

[54] Norouzi HR, Mostoufi N, Mansourpour Z, Sotudeh-Gharebagh R, Chaouki J. Characterization of solids mixing patterns in bubbling fluidized beds. Chemical Engineering Research and Design 2011;89. https://doi.org/10.1016/j.cherd.2010.10.014.

[55] Asegehegn T. Investigation of Bubble Hydrodynamics in Gas-Solid Fluidized Beds Containing Immersed Horizontal Tube Banks for Lignite Drying Application. Ph.D. Thesis. Brandenburg University of Technology. 2011.

[56] Kumar P, Parwani AK, Gupta DK, Vitankar V. Transient Cold Flow Simulation of Fast-Fluidized Bed Air Reactor with Hematite as an Oxygen Carrier for Chemical Looping Combustion. Applied Sciences 2021;11. https://doi.org/10.3390/app11052288.

[57] Engineering Toolbox. Tools and Basic Information for Design, Engineering and Construction of Technical Applications. Engineering Toolbox 2021. https://www.engineeringtoolbox.com. 


\section{Appendices}

\section{Appendix A - Model Assumptions}

1) The system is limited to a single reactor configuration.

2) All gases follow ideal gas behaviour.

3) The contents in the fluidised bed are well mixed.

4) The TCMD reaction is $1^{\text {st }}$ order and assumes separable deactivation kinetics.

5) The only products of the TCMD reaction are solid carbon and hydrogen gas.

6) The TCMD reaction only occurs on the surface of the catalyst.

7) The pre-heaters heat the inlet gas to the required reaction temperature.

8) The energy required to pre-heat the gas and fresh catalyst material is neglected.

9) The catalyst inlet and outlet flow rates are equal.

10) No energy/heat losses to the environment and no leakage.

11) Sintering occurs above $950^{\circ} \mathrm{C}$, which causes an increase in the deactivation rate.

12) Catalyst poisoning and attrition are neglected.

13) All densities and viscosities are constant.

14) Gas separation and solid separation units are ideal.

15) The time taken for catalyst cycling is instantaneous.

16) The system is limited to a maximum of 9 bar due to the limited experimental data available for model validation. 


\section{Appendix B - Model Parameters}

Table B.1. Model parameters and initial base-case model values.

\begin{tabular}{|c|c|c|c|c|}
\hline Symbol & Description & Value & Unit & Reference / Comment \\
\hline A & Frequency factor & 2,820 & $s^{-1}$ & Calculated from [42]. \\
\hline a & Catalyst activity (relative) & 1 & - & Between 1 and 0 \\
\hline $\mathrm{A}_{d}$ & $\begin{array}{l}\text { Deactivation frequency } \\
\text { factor }\end{array}$ & 315 & $s^{-1}$ & Calculated from [35]. \\
\hline$A_{d, s}$ & Sintering frequency factor & 325 & $s^{-1}$ & Determined. ( $\approx 3 \%$ change) \\
\hline $\mathrm{a}_{\text {limit }}$ & Catalyst activity limit & 0.03 & - & Determined. \\
\hline $\mathrm{A}_{r}$ & Heat transfer area & - & $\mathrm{m}^{2}$ & \\
\hline $\mathrm{a}_{S S}$ & Steady-state catalyst activity & 0.01 & - & Baerns [47]. \\
\hline$C_{j}$ & $\begin{array}{l}\text { Molar Concentration, species } \\
\text { j }\end{array}$ & - & Mol $\mathrm{m}^{-3}$ & \\
\hline$c_{p}$ & $\begin{array}{l}\text { Specific heat capacity of } \\
\text { methane }\end{array}$ & $4.475 \times 10^{-3}$ & $\mathrm{~J} \mathrm{~kg}^{-1}$ & \\
\hline$\overline{c_{p}}$ & $\begin{array}{l}\text { Average specific heat } \\
\text { capacity of solids }\end{array}$ & 616 & $\mathrm{~J}_{\mathrm{K}^{-1}}$ & Determined. \\
\hline $\mathrm{D}_{p}$ & Catalyst particle diameter & 150 & $\mu \mathrm{m}$ & Maximum Geldart Type A. \\
\hline$E_{a}$ & Activation energy & 90,368 & $\mathrm{~J} \mathrm{~mol}^{-1}$ & Calculated from [42]. \\
\hline$E_{d}$ & Deactivation energy & 96,630 & $\mathrm{~J} \mathrm{~mol}^{-1}$ & Calculated from [35]. \\
\hline$E_{d, s}$ & $\begin{array}{l}\text { Deactivation energy of } \\
\text { sintering }\end{array}$ & 93,850 & $\mathrm{~J} \mathrm{~mol}^{-1}$ & Determined. ( $\approx 3 \%$ change) \\
\hline$F_{j}$ & Molar flow rate, species j & - & $\mathrm{mol} \mathrm{s}^{-1}$ & \\
\hline$F F$ & Fluidisation factor & - & - & \\
\hline g & Gravitational acceleration & 9.81 & $\mathrm{~m} \mathrm{~s} \mathrm{~s}^{-2}$ & \\
\hline$\Delta \mathrm{G}^{\mathrm{o}}$ & $\begin{array}{l}\text { Standard change in Gibbs } \\
\text { free energy }\end{array}$ & - & $\mathrm{J} \mathrm{mol}^{-1}$ & \\
\hline$\Delta \mathrm{H}_{r}$ & Enthalpy of reaction & - & $\mathrm{J} \mathrm{mol}^{-1}$ & \\
\hline$\Delta \mathrm{H}_{r}^{\mathrm{o}}$ & $\begin{array}{l}\text { Standard enthalpy of } \\
\text { reaction }\end{array}$ & 74,800 & $\mathrm{~J} \mathrm{~mol}^{-1}$ & \\
\hline $\mathrm{K}_{\mathrm{eq}}$ & Equilibrium constant & - & - & \\
\hline $\mathrm{K}_{\mathrm{f}}$ & $\begin{array}{l}\text { Fugacity-based equilibrium } \\
\text { constant }\end{array}$ & - & - & \\
\hline $\mathrm{K}_{\mathrm{p}}$ & $\begin{array}{l}\text { Pressure-based equilibrium } \\
\text { constant }\end{array}$ & - & - & \\
\hline $\mathrm{K}_{\mathrm{x}}$ & $\begin{array}{l}\text { Mole fraction-based } \\
\text { equilibrium } \\
\text { constant }\end{array}$ & - & - & \\
\hline $\mathrm{k}$ & Rate constant & - & $s^{-1}$ & \\
\hline
\end{tabular}




\begin{tabular}{|c|c|c|c|c|}
\hline Symbol & Description & Value & Unit & Reference / Comment \\
\hline $\mathrm{k}_{d}$ & Deactivation rate constant & - & $\mathrm{s}^{-1}$ & \\
\hline $\mathrm{k}_{d, s}$ & Sintering rate constant & - & $\mathrm{s}^{-1}$ & \\
\hline$N_{\text {cycles }}$ & Number of catalyst cycles & - & - & \\
\hline $\mathrm{p}$ & Pressure & 1 & bar & Determined. \\
\hline$p_{j}$ & Partial pressure, species j & - & bar & \\
\hline$\dot{Q}$ & External heat supply & - & $\mathrm{J} \mathrm{s}^{-1}$ & \\
\hline$Q_{j}$ & $\begin{array}{l}\text { Volumetric flow rate, species } \\
\text { j }\end{array}$ & - & $\mathrm{m}^{3} \mathrm{~s}^{-1}$ & \\
\hline$r_{d}$ & Deactivation reaction rate & - & $\mathrm{mol} \mathrm{kg}^{-1}$ & \\
\hline$r_{j}$ & Reaction rate, species j & - & $\underset{\mathrm{s}^{-1}}{\mathrm{~mol} \mathrm{~kg}}$ & \\
\hline$r_{j, i}$ & $\begin{array}{l}\text { Reaction rate fresh catalyst, } \\
\text { species j }\end{array}$ & - & $\underset{\mathrm{s}^{-1}}{\mathrm{~mol} \mathrm{~kg}}$ & \\
\hline $\mathrm{R}$ & Universal gas constant & 8.314 & $\mathrm{~J} \mathrm{~mol}^{-1}$ & \\
\hline $\mathrm{T}$ & Reactor temperature & 1123 & K & Determined. \\
\hline $\mathrm{T}_{a}$ & Ambient temperature & 298 & K & \\
\hline$t$ & Time & - & s & \\
\hline U & $\begin{array}{l}\text { Overall heat transfer } \\
\text { coefficient }\end{array}$ & - & $\begin{array}{l}\mathrm{W} \mathrm{m}^{-2} \\
\mathrm{~K}^{-1}\end{array}$ & \\
\hline$U_{f}$ & Fluidisation velocity & - & $\mathrm{m} \mathrm{s}^{-1}$ & \\
\hline$U_{m f}$ & $\begin{array}{l}\text { Minimum fluidisation } \\
\text { velocity }\end{array}$ & 0.025 & $\mathrm{~m} \mathrm{~s}^{-1}$ & Calculated. \\
\hline$U_{t}$ & Terminal fluidisation velocity & 2.29 & $\mathrm{~m} \mathrm{~s}^{-1}$ & Calculated. \\
\hline V & Reactor volume & 4 & $\mathrm{~m}^{3}$ & Determined. \\
\hline$W$ & Catalyst bed mass & 150 & $\mathrm{~kg}$ & Determined. \\
\hline$X_{j}$ & Conversion, species j & - & [\%] & \\
\hline$y_{\mathrm{CH}_{4}}$ & $\begin{array}{l}\text { Mole fraction of methane at } \\
\text { inlet }\end{array}$ & 1 & - & Determined. \\
\hline$y_{\mathrm{H}_{2}}$ & $\begin{array}{l}\text { Mole fraction of hydrogen at } \\
\text { inlet }\end{array}$ & 0 & - & Determined. \\
\hline \multicolumn{5}{|c|}{ Greek Letters } \\
\hline$\tau$ & Residence time & - & s & \\
\hline$\rho_{\text {cat }}$ & Catalyst density & 5150 & $\mathrm{~kg} \mathrm{~m} \mathrm{~m}^{-3}$ & {$[56]$. } \\
\hline$\rho_{C}$ & $\begin{array}{l}\text { Solid carbon (graphite) } \\
\text { density }\end{array}$ & 2266 & $\mathrm{~kg} \mathrm{~m} \mathrm{~m}^{-3}$ & {$[57]$. } \\
\hline$\rho_{g}$ & Methane gas density & 0.1929 & $\mathrm{~kg} \mathrm{~m}^{-3}$ & {$[57]$. } \\
\hline
\end{tabular}




\begin{tabular}{clccc}
\hline Symbol & \multicolumn{1}{c}{ Description } & Value & Unit & Reference / Comment \\
\hline$\rho_{H_{2}}$ & Hydrogen gas density & 0.0242 & $\mathrm{~kg} \mathrm{~m}^{-3}$ & [57]. \\
$\overline{\rho_{S}}$ & Average solids density & 5088 & $\mathrm{~kg} \mathrm{~m}^{-3}$ & Calculated. \\
$\mu_{g}$ & Methane dynamic viscosity & $27.49 \times 10^{-6}$ & $\mathrm{~kg} \mathrm{~m}^{-1}$ & [57]. \\
& & & & \\
Subscripts & & & & \\
$e q$ & Equilibrium & & \\
$g$ & Gas phase & & \\
$i$ & Inlet/Initial & & \\
& Outlet/Final & & \\
\end{tabular}

